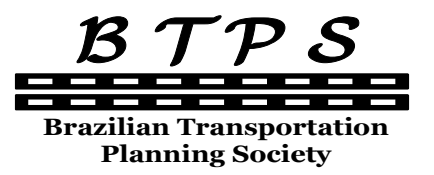

Journal of Transport Literature

Vol. 8, n. 4, pp. 187-226, Oct. 2014

Research Directory
JTL|RELIT

www.journal-of-transport-literature.org ISSN 2238-1031

\title{
Custos e fretes praticados no transporte rodoviário de cargas: uma análise comparativa entre autônomos e empresas
}

\author{
[Costs and freights charged in road cargo transportation: \\ a comparative analysis between owner operators and companies]
Maria da Penha S. Araújo, Renata Albergaria de Mello Bandeira*, Vania Barcellos Gouvea Campos
Military Institute of Engineering - Brazil

Submitted 22 Mar 2013; received in revised form 11 Mar 2014; accepted 3 Apr 2014

\begin{abstract}
Resumo
0 presente estudo tem como principal propósito investigar a hipótese de que existem diferenças entre os valores de fretes praticados pelos principais atores envolvidos no transporte rodoviário de cargas no Brasil (empresas e autônomos), sendo o principal problema o valor pago ao autônomo, que, na maioria das vezes, é contratado por empresas transportadoras. Além de investigar esta hipótese de pesquisa, o estudo também se propõe a analisar se a diferença entre os fretes pagos é indevida ou não, identificando as principais causas para esta suposta diferença. A importância deste estudo está no fato de que este tipo de análise, apesar de relevante, ainda não ter sido observado na literatura nacional. Desta forma, a partir de um estudo das metodologias de formação de preços de frete e de uma pesquisa de campo com 20 empresas transportadoras e 96 autônomos, procurou-se identificar as possíveis diferenças em relação ao valor do frete pago e o valor dos custos inerentes à operação do transporte, tomando-se como objeto de análise o eixo São Paulo a Rio de Janeiro no transporte de carga geral. A pesquisa de metodologias de cálculo de frete possibilitou identificar os custos envolvidos nesta operação, bem como todas as características e peculiaridades deste ofício, propondo-se um método de cálculo que inclui todos os custos envolvidos na operação de transporte. Com a metodologia proposta, foi possível determinar o valor do preço final do frete que seria suficiente para remunerar todos os gastos percebidos pelos diferentes atores em seus trabalhos. Também foram realizadas comparações entre os fretes reais praticados por transportadores autônomos e os valores que deveriam ser praticados caso todos os custos operacionais do transporte fossem, de fato, aplicados. Enfim, verificou-se que a diferença de valores de frete existe, porém, com base na pesquisa, observou-se que esta diferença é coerente em função dos custos relativos às empresas e aos autônomos. Além disso, foi possível observar que existe uma baixa lucratividade para todos os atores deste mercado, havendo indícios de que os autônomos realmente são os mais prejudicados.
\end{abstract}

Palavras-Chave: transporte rodoviário de cargas, fretes, transportadores autônomos.

\begin{abstract}
The present study aims to investigate the hypothesis that there are discrepancies between the freights charged by the major actors involved in cargo road transportation in Brazil (companies, carrier owners and cooperative). Therefore, the present study aims to identify possible distortions in the freight rates paid and the costs inherent in the operation, considering the transport of general cargo from São Paulo to Rio de Janeiro as the object of study. Consequently, different methodologies for calculating freights of cargo transportation were analyzed in order to identify the costs involved in this type of operation, as well as all the features and peculiarities involved, defining a method of calculation of all costs involved in this type of transport operation. As a result, it became possible to estimate a final freight value that would be fair to pay all costs involved in the transport operation. Comparisons were also made between the actual freight charged by owner operators and the values that should be practiced in fact if they actually managed all operating costs of transport. Finally, a reduction in profitability was verified for all players in this market, but there are indications that carrier owners are the most harmed.
\end{abstract}

Key words: road cargo transportation, freights, owner operators.

*Email: re.albergaria@gmail.com.

\section{Recommended Citation}

Araújo, M. P. S., Bandeira, R. A. M. and Campos, V. B. G. (2014) Custos e fretes praticados no transporte rodoviário de cargas: uma análise comparativa entre autônomos e empresas. Journal of Transport Literature, vol. 8, n. 4, pp. 187-226. 


\section{Introdução}

O transporte rodoviário tem sido a preferência na movimentação interna de cargas no Brasil. A produção nacional de transporte (quantidade movimentada x distância percorrida) possui mais de $60 \%$ de participação do transporte rodoviário de cargas e, considerando apenas as cargas conteinerizáveis, essa parcela chega a 90\% de participação (Wanke, 2010).

A preferência pelo transporte rodoviário tem fundamentos logísticos, tal como a pulverização da malha viária. Porém, também existem diversos fatores que favorecem indevidamente a opção pelo transporte rodoviário no Brasil (ANTT, 2012): (i) prática de excesso de carga, que acarreta na destruição da malha rodoviária nacional e em maiores custos de manutenção; (ii) falta de regulamentação da jornada de trabalho do motorista, permitindo que a viagem seja feita mais rapidamente e, conseqüentemente, reduzindo custos, ao mesmo tempo em que sacrifica o motorista e contribui para o aumento do número de acidentes de trânsito (cerca de $30 \%$ dos acidentes de trânsito no país tem caminhões envolvidos); (iii) sonegação de impostos, devido à ineficiência no controle da emissão de conhecimento de transporte ou mesmo da nota fiscal dos produtos transportados por autônomos; (iv) prática da carta-frete; e (v) prática de cobrança de fretes abaixo do custo, o que impede a renovação da frota (que tem idade média de 19 anos) e acarreta em consequiências desastrosas para o consumo de combustível, poluição e acidentes.

Entretanto, também existe uma série de dificuldades estruturais no sistema rodoviário. $\mathrm{O}$ tráfego, por exemplo, se dá em rodovias em mal estado de conservação, o que compromete a segurança da operação e a torna mais onerosa (CNT, 2010). Além disto, devido aos baixos preços cobrados pelos transportadores rodoviários de cargas autônomos no Brasil, observa-se uma maior dificuldade na utilização de outros modos de transportes e na sua integração, o que acaba gerando externalidades negativas para a sociedade (CNT, 2002).

Os baixos fretes rodoviários praticados no mercado brasileiro são conseqüência da excessiva oferta de serviços de transportadores autônomos, que, em sua maioria, são contratados por grandes transportadoras. Empresas transportadoras, em geral, são contratadas por fabricantes de produtos para transportar matéria prima até os parques industriais ou sua produção final até 
os mercados consumidores. Como forma de reduzir custos e otimizar rotas, as empresas transportadoras acabam por terceirizar novamente este serviço para transportadores autônomos, que praticam preços abaixo do considerado recomendável sob a ótica econômicofinanceira. As baixas receitas oriundas destes fretes com preços distorcidos acarretam em problemas de manutenção veicular, jornadas de trabalho excessivas, sobrecarga nos veículos, incapacidade de renovação de frota, aumento da idade média da frota, aumento do índice de acidentes, inadimplência fiscal e, conseqüentemente, em diversos impactos para a sociedade, no que pode ser chamado de "Círculo Vicioso" do Transporte Rodoviário de Cargas no Brasil (ANTT, 2012). Dentre os impactos gerados, pode-se enumerar o aumento no índice de acidentes e mortes, emissão excessiva de poluentes, engarrafamentos e maior consumo de combustível (CNT, 2002).

Ainda assim, a atividade de transportes no Brasil vem aumentando sua participação no Produto Interno Bruto (PIB) do país, crescendo de 3,7\% para 4,3\% entre 1985 e 1999 (Fleury, 2003). Entre 1970 e 2000, o setor de transportes cresceu cerca de $400 \%$, enquanto o aumento do PIB foi de $250 \%$. Este crescimento foi fortemente influenciado pela desconcentração geográfica da economia brasileira nas últimas décadas, na direção das regiões Centro-Oeste, Norte e Nordeste. Desta forma, o atual crescimento econômico brasileiro apresenta o setor de transportes como uma excelente oportunidade de investimentos, sendo, portanto, importante conhecer o cenário atual deste mercado.

Neste contexto, o presente estudo, inicialmente, apresenta o panorama atual do transporte rodoviário de cargas no Brasil e, em especial, analisa o mercado de fretes rodoviários no país. Esta etapa do estudo teve como objetivo identificar o corredor de transporte a ser pesquisado, visando à realização de uma análise comparativa do frete entre os principais atores do mercado de transportes de carga (autônomos transportadoras e cooperativas). A partir desta análise, foi escolhido o eixo São Paulo - Rio de Janeiro devido a sua grande representatividade na movimentação de cargas no Brasil, conforme explicado na Seção 4. Em seguida, realizou-se uma revisão de diferentes metodologias para o cálculo do frete rodoviário de carga com base na composição de custos, propondo-se um método de cálculo incluindo todas as variáveis de custos envolvidas na operação de transporte, que possibilitou determinar o valor do frete que seria suficiente para remunerar todos os gastos percebidos pelo transportador autônomo e pelas empresas transportadoras em seu trabalho. Finalmente, foi 
realizada uma pesquisa de campo com empresas transportadoras e autônomos que atuam neste corredor, que permitiu uma análise comparativa entre os fretes reais cobrados e os valores que deveriam ser praticados de fato. Como resultado, foi possível verificar que a comoditização do produto de transporte gera a redução da lucratividade de todos os atores envolvidos nesta atividade. Entretanto, a maior distorção observada foi entre os valores praticados pelos autônomos e aquele calculado caso todos os custos operacionais do transporte fossem gerenciados de maneira correta, havendo indícios então de que os autônomos estão sendo ainda mais prejudicados.

\section{O Mercado de Transporte Rodoviário no Brasil}

Historicamente, o Brasil teve sua malha viária fortemente voltada para o modo rodoviário de transportes. O transporte rodoviário de cargas é responsável por seis de cada dez quilos de carga distribuída no país e, em 2010, movimentou 1,2 bilhões de toneladas, apresentando um crescimento de 5,1\% comparado a 2009 (CNT, 2011).

O modal rodoviário deveria se concentrar no transporte de produtos industrializados, de alto a médio valor agregado, com pequenos volumes e em rotas de pequena distância. Porém, no Brasil, devido ao baixo valor do frete, acaba sendo um importante player no transporte de commodities como soja, derivados de petróleo e cimento.

Atualmente, o mercado brasileiro de transporte rodoviário envolve a participação de 127 mil empresas de transporte de cargas (ETC), 671 mil autônomos (TAC) e 623 cooperativas (CTC), gerando mais de 3,5 milhões de empregos (ANTT, 2012). A Tabela 1 apresenta dispersão geográfica dos principais atores que operam no mercado de transporte rodoviário de carga no Brasil.

Os autônomos são responsáveis por grande parte dos caminhões em circulação no país e pelo transporte de mais de $60 \%$ das cargas. Porém, a maior parte desses profissionais trabalha sem contrato e muitos sequer têm conta bancária (ANTT, 2012). Em geral, os transportadores autônomos operam em parceria com transportadoras que, apesar de possuírem frota própria, na prática, costumam lançar mão de transportadores autônomos. Algumas optam pela 
terceirização apenas em épocas de pico, mas outras empresas a praticam de maneira sistemática, com intuito de reduzir suas despesas (dos Reis, 2001).

Tabela 1 - Quantidade de transportadores por região ${ }^{1}$

\begin{tabular}{|c|c|c|c|c|c|c|}
\hline Quantidade de Transportadores & $\mathrm{CO}$ & $\mathrm{NE}$ & $\mathrm{N}$ & $\mathrm{SE}$ & $\mathrm{S}$ & Total \\
\hline \multirow{2}{*}{ TAC } & & & & & & \\
\hline & 52.439 & 89.557 & 18.974 & 342.582 & 168.229 & 671.781 \\
\cline { 2 - 8 } & $7,8 \%$ & $13,3 \%$ & $2,8 \%$ & $51 \%$ & $25,0 \%$ & \\
\hline \multirow{2}{*}{ ETC } & 7.193 & 13.448 & 5.088 & 60.196 & 41.670 & 127.595 \\
\cline { 2 - 7 } & $5,6 \%$ & $10,5 \%$ & $4,0 \%$ & $47,2 \%$ & $32,7 \%$ & \\
\hline \multirow{2}{*}{ CTC } & 28 & 76 & 32 & 221 & 266 & 623 \\
\cline { 2 - 7 } & $4,5 \%$ & $12,2 \%$ & $5,1 \%$ & $35,5 \%$ & $42,7 \%$ & $100 \%$ \\
\hline
\end{tabular}

Com a terceirização, as empresas transportadoras buscam reduzir investimentos, evitar ociosidade da frota e reduzir custos. Como a propriedade do caminhão deixa de ser de responsabilidade da empresa, passando a ser instrumento de trabalho dos caminhoneiros, a terceirização representa uma forma de capitalização mais flexível. Assim, o investimento e manutenção, bem como os demais custos de operação, que eram responsabilidade da empresa, são repassados para o caminhoneiro autônomo (Valente et al., 2011; Chahad e Cacciamali, 2005). Contudo, algumas desvantagens da prática da terceirização também devem ser consideradas, como: a necessidade de maior gerenciamento de tráfego, idade dos veículos, dificuldades de contratação etc. Entretanto, tais problemas podem ser reduzidos por meio de práticas como: clareza nos contratos, conferência de carga e rastreamento do veículo.

É importante ressaltar que alguns caminhoneiros se organizam em cooperativas para a prestação do serviço de frete. Em uma cooperativa típica, um grupo de caminhoneiros, proprietários de seus veículos, oferece o serviço de forma coletiva. Os caminhoneiros se alternam no transporte e a renda auferida é dividida entre os cooperados. É a cooperativa que assina o contrato de prestação de serviço e cumpre as formalidades legais. Atualmente, as cooperativas de transporte de carga possuem uma frota de 11 mil veículos com idade média de 14,4 anos (RNTRC, 2011). Para o profissional autônomo, pertencer a uma cooperativa tem a vantagem de reduzir os riscos e os custos da atividade e aumentar o valor agregado do serviço. Ainda, a cooperativa, constituída como pessoa jurídica, tem condições melhores do

\footnotetext{
${ }^{1}$ Fonte: Adaptado de Cibulska et al. (2010).
} 
que o caminhoneiro individual para negociar a contratação do serviço de frete, adquirir seguro para seus associados, realizar convênios com oficinas mecânicas, realizar treinamentos, etc.

\section{O Mercado de Fretes Rodoviários no Brasil}

A formação do preço do transporte é bastante complexa, pois, além dos custos da atividade, incorpora também fatores locais e conjunturais (Martins, 2008). Ortúzar e Willunsen (1994) e Caixeta Filho et al. (2011) listam uma série de variáveis que influenciam no estabelecimento do preço do frete, a saber: (i) distância percorrida; (ii) especificidade da carga transportada e do veículo utilizado; (iii) prazo de entrega da carga; (iv) custos operacionais; (v) sazonalidade da demanda; (vi) perdas e avarias; (vii) características e aspectos geográficos das vias utilizadas; (vii) pedágios; e (viii) a possibilidade da carga de retorno para as zonas de origem.

O preço do frete pode ainda se diferenciar de acordo com a rota. Uma região onde há maior demanda pelo transporte possui fretes mais caros (Hijjar, 2008). As rotas com origem em São Paulo, por exemplo, costumam ser mais caras do que aquelas que têm este ponto como destino (Lima, 2006). O frete da carga movimentada do Rio de Janeiro para São Paulo é, em média, 44\% mais baixo do que o inverso da rota. Acredita-se que este fenômeno se deve, em parte, ao fato de São Paulo ser o maior pólo industrial do país e, portanto necessita escoar sua produção para as demais regiões.

São diversos os fatores que influenciam na formação de preços dos fretes. No Brasil, um cenário de poucas exigências para a operação e baixa fiscalização levou a redução da qualidade dos serviços prestados e dos preços do frete praticados no mercado de transporte rodoviário de cargas no país (Hijjar, 2008). Este setor não passa por um mecanismo de controle governamental, permitindo que os preços sejam formados a partir da negociação direta entre a oferta e a procura pelo serviço (Soares e Caixeta Filho, 1997). Assim, o excesso de oferta, combinado com a falta de regulação adequada, faz com que o preço do transporte rodoviário no país esteja inferior ao padrão americano. O transporte rodoviário no país possui uma tarifa média que é $46 \%$ da americana (ANTT, 2012). A Tabela 2 apresenta a comparação da composição do custo do transporte rodoviário brasileiro em relação ao norte americano. 
Observa-se, por meio da Tabela 2, o baixo custo de motorista na composição do frete no Brasil. Este é o resultado da falta de legislação sobre condições de trabalho, que leva motoristas autônomos a cumprirem jornadas de trabalho extremamente longas (Fleury, 2013). Por sua vez, os altos custos de pneus e manutenção são conseqüência do mau estado de conservação de nossas rodovias, enquanto o maior custo de combustível é reflexo do grande aumento no preço do petróleo nos últimos anos.

\section{Tabela 2 - Composição do Custo do Transporte Rodoviárioº}

\begin{tabular}{|c|c|c|}
\hline Itens de custo & EUA & Brasil \\
\hline Motorista & $30 \%$ & $16 \%$ \\
\hline Veículo & $20 \%$ & $19 \%$ \\
\hline Combustível & $19 \%$ & $26 \%$ \\
\hline Pneus & $3 \%$ & $11 \%$ \\
\hline Manutenção & $8 \%$ & $14 \%$ \\
\hline Overhead & $20 \%$ & $14 \%$ \\
\hline
\end{tabular}

Há, no Brasil, uma insatisfação geral dos transportadores rodoviários quanto aos preços dos fretes recebidos, devido à falta de regularidade da evolução dos custos operacionais em relação ao preço do frete praticado, ocasionando impacto direto na margem de lucro na atividade (Caixeta Filho, 2011). Desta forma, Hijjar (2008) realizou um estudo comparativo entre as tarifas praticadas no mercado e aquela necessária para cobrir todos os custos e garantir uma margem de ganho para o transportador, a qual denomina de tarifa referencial, observando as distorções apresentadas na Figura 1.

Verifica-se, a partir da Figura 1, que, no transporte de carga seca por truck e carreta, o preço médio pago pelo frete é mais baixo do que as tarifas referenciais. Esta distorção é influenciada pela grande atuação de transportadores autônomos. Em relação às carretas Baú, observa-se uma tarifa praticada mais alta, isto, possivelmente, se deve ao fato de que, nesta categoria, é pequena a participação dos transportadores autônomos. Existe uma grande disponibilidade de veículos de transportadores autônomos no mercado, o que gera maior concorrência, que é agravada pelo baixo controle exercido pelo governo para a entrada de novos trabalhadores autônomos no mercado. Assim, as empresas, cientes desta concorrência, acabam se beneficiando deste excesso de oferta e impõem aos autônomos os valores que elas acham justos. Estes valores fazem parte de uma tabela de preços predeterminada ("tabela fechada"),

\footnotetext{
${ }^{2}$ Fonte: Adaptado de Fleury (2003).
} 
que é utilizada pelas empresas para a contratação do serviço dos transportadores autônomos, não havendo, portanto, margem para negociação. De tal modo, tais valores nem sempre remuneram adequadamente os custos inerentes à operação efetuada pelo caminhoneiro, tal como pode ser observado na Figura 1.

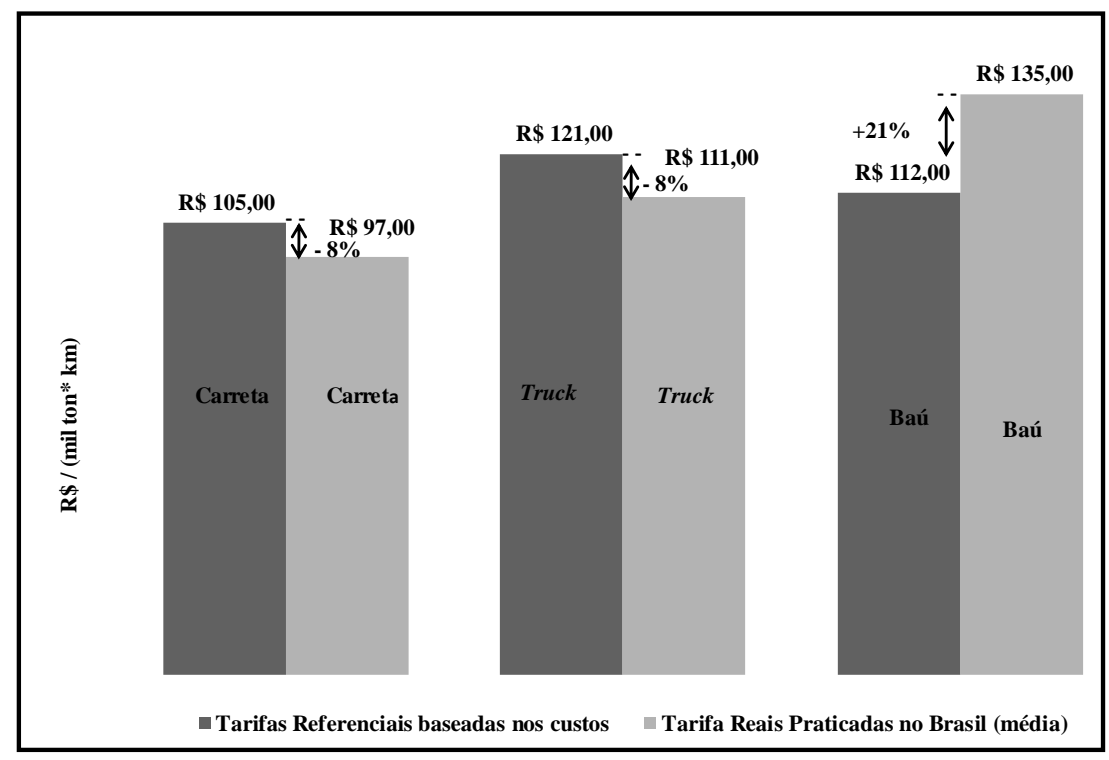

Figura 1 - Comparação entre Preço e Custo ${ }^{3}$

Existem diferentes tipos de métodos que podem ser adotados para o cálculo do frete de transporte: métodos voltados para a concorrência, métodos voltados para demanda e métodos voltados para custos (Souza e Rocha, 2010). Por meio dos métodos voltados para concorrência, as empresas estabelecem o valor do frete a partir de um levantamento dos preços de mercado (concorrentes), estabelecendo o seu preço mediante as práticas de mercado. O método voltado para demanda leva em consideração o quanto o consumidor está disposto a pagar pelo serviço. Porém, a disponibilidade de dados e informações sobre a elasticidade da demanda é muito escassa, dificultando sua utilização no setor de transportes (Teixeira Filho, 2001). Enfim, o método voltado para custos estabelece uma margem sobre os custos esperados, obtidos por meio da apropriação ou por metodologias clássicas de contabilidade de custos. Desta forma, a Seção 3 aborda a sistemática de cálculos dos custos inerentes ao transporte rodoviário de cargas, bem como a estrutura de custeio desta atividade.

\footnotetext{
${ }^{3}$ Fonte: Adaptado de Hijjar (2006).
} 


\section{Cálculo dos custos do transporte rodoviário de cargas}

A partir de uma metodologia adequada para cálculo do custeio do frete, pode-se contribuir para formação de preços justos, tanto para empresa quanto para o transportador (Lima, 2003). Desta forma, esta pesquisa analisa diferentes metodologias para o cálculo do frete rodoviário de carga com base na composição de custos. Foram analisadas metodologias propostas por instituições, tais como GEIPOT, empresas transportadoras, cooperativas, instituições de pesquisas, dentre outros. No entanto, tais metodologias possuem diferenças entre si:

- Planilha da COPPEAD: observa-se, pela análise da planilha disponibilizada por esta instituição, que foram considerados, em seus estudos, apenas as despesas diretas que são formadas basicamente pelos custos fixos e variáveis. Não foram considerados os custos indiretos que são inerentes à operação do transporte (www.coppead.ufrj.br);

- Planilha GEIPOT: esta planilha de cálculo foi desenvolvida em 1999 por este órgão do Governo Federal. As variáveis consideradas também ficaram restritas às despesas diretas, considerando como despesas indiretas apenas os salários e ordenados da diretoria e outros custos (www.geipot.gov.br).

- Manual da NTC: a Associação Nacional de Transporte de Carga (NTC) e a Fundação Instituto de Pesquisa Econômica (FIPE), em 1990, desenvolveram uma planilha de cálculos que é composta por todos os índices das operações de transporte, acrescidos dos índices da variação do custo de coleta e entrega de mercadorias. Este instrumento é adotado como referência para grande parte das empresas e cooperativas de transporte cargas no Brasil (www.ntc.org.br).

- Planilha da Cooperativa: esta planilha foi desenvolvida por uma cooperativa de transporte de carga, pesquisada neste trabalho, e, também, se restringe às despesas diretas, sendo que alguns custos diretos, normalmente utilizados em outros manuais, não são considerados nos cálculos, tornando-a bastante simplificada.

- Guia do Transportador: trata-se de um portal eletrônico que permite acesso a uma planilha de cálculos do frete, apenas para assinantes do site. A planilha se restringe às despesas diretas, o que torna o método de cálculo bastante simplificado (www.guiadotrc.com.br). 
A Tabela 3 apresenta uma comparação entre as variáveis de custos consideradas por cada uma das metodologias analisadas.

Tabela 3 - Análise das planilhas de cálculo de frete

\begin{tabular}{|c|c|c|c|c|c|}
\hline Itens de Custos Considerados & Coopead & Geipot & NTC & $\begin{array}{c}\text { Coopera- } \\
\text { tiva }\end{array}$ & $\begin{array}{c}\text { Guia do } \\
\text { Transpor- } \\
\text { tador } \\
\end{array}$ \\
\hline \multicolumn{6}{|l|}{ 1. Despesas Diretas } \\
\hline \multicolumn{6}{|l|}{ 1.1 Custos Variáveis } \\
\hline Peças, acessórios e material de manutenção & $\mathrm{x}$ & $\mathrm{x}$ & $\mathrm{x}$ & & \\
\hline Pedágios - Trecho & & & $\mathrm{x}$ & & \\
\hline Óleo diesel, de carter e de câmbio/diferencial & $\mathrm{x}$ & $\mathrm{X}$ & $\mathrm{x}$ & $\mathrm{x}$ & $\mathrm{x}$ \\
\hline Pneumáticos (pneus) & $\mathrm{x}$ & & $\mathrm{x}$ & $\mathrm{x}$ & $\mathrm{x}$ \\
\hline Manutenção (reparos no veículo) & $\mathrm{x}$ & $\mathrm{x}$ & $\mathrm{x}$ & $\mathrm{x}$ & $\mathrm{x}$ \\
\hline Lavagem e engraxamento & & & $\mathrm{x}$ & $\mathrm{x}$ & $\mathrm{x}$ \\
\hline \multicolumn{6}{|l|}{ 1.2 Custos Fixos } \\
\hline Remuneração de Capital & $\mathrm{x}$ & & $\mathrm{x}$ & $\mathrm{x}$ & $\mathrm{x}$ \\
\hline Reposição do Veículo & $\mathrm{x}$ & $\mathrm{x}$ & $\mathrm{x}$ & $\mathrm{x}$ & $\mathrm{x}$ \\
\hline Reposição do Equipamento & & $\mathrm{x}$ & $\mathrm{x}$ & & \\
\hline Custo da Apólice & $\mathrm{x}$ & $\mathrm{x}$ & $\mathrm{x}$ & $\mathrm{x}$ & $\mathrm{x}$ \\
\hline Seguro do veículo (Incêndio/colisão/roubo) & & $\mathrm{x}$ & & $\mathrm{x}$ & $\mathrm{x}$ \\
\hline Responsabilidade Civil Facultativa - DM/DP & $\mathrm{x}$ & $\mathrm{x}$ & $\mathrm{x}$ & $\mathrm{x}$ & $\mathrm{x}$ \\
\hline Seguro do equipamento & & & $\mathrm{x}$ & & \\
\hline IPVA/DPVAT & $\mathrm{x}$ & $\mathrm{x}$ & $\mathrm{x}$ & $\mathrm{x}$ & $\mathrm{x}$ \\
\hline Licenciamento anual & $\mathrm{x}$ & $\mathrm{x}$ & $\mathrm{x}$ & $\mathrm{x}$ & $\mathrm{x}$ \\
\hline Salários e encargos (motorista) & $\mathrm{x}$ & $\mathrm{x}$ & $\mathrm{x}$ & $\mathrm{x}$ & $\mathrm{x}$ \\
\hline Salários e encargos (oficina) & & $\mathrm{x}$ & $\mathrm{x}$ & & \\
\hline Padronização (pinturas, adesivos, logomarca) & & & $\mathrm{x}$ & & \\
\hline
\end{tabular}


Tabela 3 - Análise das planilhas de cálculo de frete (cont.)

\begin{tabular}{|c|c|c|c|c|c|}
\hline Itens de Custos Considerados & Coopead & Geipot & NTC & $\begin{array}{c}\text { Coopera- } \\
\text { tiva }\end{array}$ & $\begin{array}{c}\text { Guia do } \\
\text { Transpor- } \\
\text { tador }\end{array}$ \\
\hline \multicolumn{6}{|l|}{ 2. Despesas Indiretas } \\
\hline 2.1 Salários, Ordenados e honorários de diretoria & & $\mathrm{x}$ & $\mathrm{x}$ & & \\
\hline \multicolumn{6}{|l|}{ 2.2 Salários Profissionais de Escritório e oper. de CD } \\
\hline 2.3 Aluguéis & & & $\mathrm{x}$ & & \\
\hline \multicolumn{6}{|l|}{ 2.4 Tarifas de Serviços Públicos } \\
\hline Água & & & $\mathrm{x}$ & & \\
\hline Energia Elétrica & & & $\mathrm{x}$ & & \\
\hline Correios e Courriers & & & $\mathrm{x}$ & & \\
\hline Telefone (fixo, celular e rádios) e Internet & & & $\mathrm{x}$ & & \\
\hline Custos de Serviços Públicos & & & $\mathrm{x}$ & & \\
\hline \multicolumn{6}{|l|}{ 2.5 Serviços Profissionais Terceirizados } \\
\hline Serviço de manutenção, conservação e limpeza & & & $\mathrm{x}$ & & \\
\hline Serviços profissionais de terceiros & & & $\mathrm{x}$ & & \\
\hline Serviços de processamento de dados & & & $\mathrm{x}$ & & \\
\hline Serviços de atendimento ao cliente (SAC) & & & $\mathrm{x}$ & & \\
\hline \multicolumn{6}{|l|}{ Serviço de Rastreamento por satélite } \\
\hline \multicolumn{6}{|l|}{ Serviço de Escolta Armada e Gerenciamento de Risco } \\
\hline \multicolumn{6}{|l|}{ Serviço de Oficina Mecânica (mão de obra) } \\
\hline \multicolumn{6}{|l|}{ Agenciador de frete } \\
\hline \multicolumn{6}{|l|}{2.6 Impostos e taxas } \\
\hline PIS - Programa de Integração Social & & & $\mathrm{x}$ & & \\
\hline COFINS- Contribuição $\mathrm{p} /$ financiamento e seguridade social & & & $\mathrm{x}$ & & \\
\hline CSLL - Contribuição Social sobre o lucro & & & $\mathrm{x}$ & & \\
\hline ICMS - Imp. s/ circul.de mercadorias e prestação de serviço & & & $\mathrm{x}$ & & \\
\hline IR - Imposto de renda & & & $\mathrm{x}$ & & \\
\hline IPTU - Imposto predial territorial urbano & & & $\mathrm{x}$ & & \\
\hline \multicolumn{6}{|l|}{ 2.7 Depreciações } \\
\hline Depreciação de máquinas e equipamentos & & & $\mathrm{x}$ & & \\
\hline Depreciação de móveis e utensilios & & & $\mathrm{x}$ & & \\
\hline \multicolumn{6}{|l|}{2.8 Outros Custos } \\
\hline Material de escritório e limpeza & & $\mathrm{x}$ & $\mathrm{x}$ & & \\
\hline Viagens, estadia e condução & & & $\mathrm{x}$ & & \\
\hline Despesas legais e judiciais & & & $\mathrm{x}$ & & \\
\hline Contribuições e doações & & & $\mathrm{x}$ & & \\
\hline Uniformes & & & $\mathrm{x}$ & & \\
\hline Despesas com promoções, brindes e propaganda & & & $\mathrm{x}$ & & \\
\hline Despesas com conservação de bens e instalações & & & $\mathrm{x}$ & & \\
\hline Despesas diversas & & & $\mathrm{x}$ & & \\
\hline Refeições e lanches & & & $\mathrm{x}$ & & \\
\hline Cópias Xerox & & & $\mathrm{x}$ & & \\
\hline Paletização de cargas & & & $\mathrm{x}$ & & \\
\hline
\end{tabular}


Observa-se que o manual da NTC é o que apresenta a maior quantidade de variáveis de análise. Esta é a única metodologia, dentre as apresentadas, que considera todas as despesas indiretas envolvidas no processo de transporte de cargas. Outro ponto de destaque é que esta metodologia é específica para o transporte rodoviário de cargas, e, por isto, serve como referência para a maioria das empresas deste ramo de atuação nos seus planejamentos operacionais e nos processos de tomada de decisão, bem como base para o desenvolvimento de estudos acadêmicos sobre o assunto, tais como Silva (2006), Batti (2009), Teixeira (2007), Caldas e Caldas (2004) e ABTI (2012). Contudo, cabe salientar que, para a análise dos fretes realizada no eixo São Paulo - Rio de Janeiro (Seção 5), não foi adotada apenas a planilha da NTC. A planilha proposta para a análise dos fretes realizada neste estudo é o resultado de um apanhado geral de todos os itens de custos considerados pelas metodologias apresentadas na Tabela 3. Os elementos de custos considerados na composição básica da tarifa rodoviária de cargas, adotados na análise dos fretes neste artigo, são detalhados na aplicação apresentada na Seção 5 .

\section{Metodologia de Pesquisa}

Para analisar as possíveis distorções entre o frete praticado e aquele calculado com base nas variáveis apresentadas na tabela 3, realizou-se uma pesquisa com empresas e autônomos que atuam no eixo São Paulo-Rio de Janeiro. Esta pesquisa teve como objetivo verificar possíveis distorções entre os preços praticados no mercado e os custos de operação do transporte rodoviário de cargas. Para isto, utilizou-se um procedimento de cálculo do frete de transporte com base nos custos, adotando-se o eixo São Paulo- Rio de Janeiro como objeto de estudo, visando determinar o preço final do frete que seria justo para remunerar todos os gastos percebidos pelas empresas transportadoras e pelo transportador autônomo em seu trabalho. Desta forma, foi possível realizar comparações entre os fretes reais e os valores que deveriam ser praticados com base em todos os custos operacionais do transporte rodoviário de cargas (Seção 5). Esta comparação permite uma análise deste mercado, averiguando se os valores recebidos se encontram em parâmetro proporcional aos custos inerentes à atividade e identificando, caso a remuneração esteja abaixo do que seria o correto, quais as variáveis de custos são ignoradas por estes profissionais em seus cálculos. Também é possível identificar quais itens de custos mais contribuem para a variação no preço final do frete. 
A escolha da região Sudeste, em especial o eixo com origem em na cidade São Paulo e destino na cidade do Rio de Janeiro pela Via Dutra, como objeto de estudo se justifica pela expressiva movimentação de cargas neste sentido. Isto pode ser explicado pela alta concentração de indústrias no Estado de São Paulo que necessita escoar sua produção para o segundo maior mercado consumidor do país, o Rio de Janeiro. Por sua vez, o Estado do Rio de Janeiro, que apresenta um reduzido parque industrial, precisa adquirir bens de consumo de outros mercados produtores, sendo o maior deles o Estado de São Paulo. Por se tratarem de bens de médio e alto valor agregado, onde o transporte rodoviário é priorizado no Brasil, a principal via rodoviária (Rodovia Presidente Dutra ou Via Dutra) de ligação entre estes mercados acaba tendo uma grande movimentação de mercadorias no sentido Rio de Janeiro. Atualmente, existem 120 transportadoras que atuam neste eixo rodoviário, que, juntas, são responsáveis por 30\% da carga movimentada na Região Sudeste. Em 2011, a região Sudeste foi responsável por $56,4 \%$ do PIB nacional, com destaque para o parque industrial diversificado e o setor de comércio e serviços (NTC, 2011).

Cabe destacar que a coleta de informações junto ao mercado de transporte foi uma tarefa complexa à medida que este mercado é bastante competitivo e evita repassar as informações para desconhecidos. Para a obtenção dos dados e informações necessárias para o cálculo do frete com base nos custos, foi realizada uma pesquisa de mercado com fornecedores e também entrevistas com empresas transportadoras e transportadores autônomos que atuam no eixo São Paulo - Rio de Janeiro. Essas entrevistas também foram fundamentais para determinar os fretes reais praticados no mercado de transporte rodoviário de cargas no eixo estudado. Foram realizadas entrevistas em 20 transportadoras (responsáveis pelo transporte de $60 \%$ da carga no eixo analisado) e 96 transportadores rodoviários autônomos (tamanho da amostra calculado com um nível de significância de $95 \%$ e erro de $10 \%$, sendo a população total de autônomos que atuam no Brasil igual a 671.000, dos quais 51\% operam na Região Sudeste). Maiores detalhes sobre o resultado destas entrevistas são apresentados em Araújo et al. (2012). 


\section{Análise dos Custos de Transporte no eixo SP - RJ}

Nesta seção, são apresentados os cálculos para composição do frete rodoviário de carga geral no eixo São Paulo a Rio de Janeiro, com base em dados e informações obtidas por meio de uma pesquisa realizada no mercado de fornecedores do transporte rodoviário de carga.

\subsection{Cálculos dos Custos de Operacionais de Transporte}

Destaca-se que este estudo reuniu todos os itens de custo presentes nas metodologias analisadas (Tabela 3). Ainda, os custos dos insumos operacionais, adotados como base de cálculo, foram obtidos no mercado de venda de produtos para o ramo do transporte de cargas ou por meio das entrevistas realizadas.

Para fazer esta análise, foi necessário, inicialmente, fazer uma previsão da demanda no eixo Rio-São Paulo. Verificou-se que neste corredor, a carga geral (também conhecida como carga seca) é o tipo de carga mais transportada, representando $47 \%$ de toda a carga movimentada na região (IBGE, 2011). Logo, tomando-se como base a movimentação de carga neste eixo em 2011 (4.632.000 toneladas anuais) (IBGE, 2011), considera-se para esta pesquisa a demanda de 2.186.304 toneladas anuais de carga geral.

\subsubsection{Características do Fluxo de Transporte}

De modo a calcular os valores relativos à movimentação de carga geral, foram pesquisados os custos, especificações e dados operacionais relativos à atividade de transporte no eixo considerado pelo estudo. Estes dados são apresentados em quatro grupos principais relativos ao veículo, à carga, à rota e à operação.

\section{- Dados do Veículo}

O veículo considerado no estudo foi a carreta três eixos, pois tanto as empresas quanto os autônomos utilizam intensivamente este tipo de veículo no eixo considerado, devido à sua flexibilidade operacional e razoáveis custos de aquisição. Este veículo possui um peso bruto total (PBT) de 39 toneladas, considerando-se o cavalo trator, o semi-reboque, os equipamentos e a carga total. Com carga total, este veículo consegue desempenhar um rendimento de 2,2 quilômetros/litro de óleo diesel comum e, em média, permanece disponível 93\% do tempo, se considerada a necessidade de parada do veículo por dois dias a cada 30 dias 
de trabalho para efetuar pequenas manutenções, lubrificações, ajustes mecânicos, lavagens e demais averiguações necessárias ao bom funcionamento do mesmo.

Segundo Scania (2012), o valor médio de aquisição deste veículo novo equivale a R\$ $350.000,00$ o conjunto completo, sendo $\mathrm{R} \$ 280.000,00$ o cavalo mecânico e $\mathrm{R} \$ 70.000,00$ o semi-reboque do tipo carroceria de madeira aberta, apropriada para carga seca. Sua taxa de valor residual é de $20 \%$ do valor inicial e sua vida econômica é de cinco anos, quando se deve substituí-lo por outro veículo novo. A Tabela 4 sintetiza os dados relativos ao veículo considerado no estudo.

\section{- Dados da Carga}

A carga considerada pelo estudo foi a carga geral ou seca, devido à sua grande movimentação no eixo e pelo fato de ser transportada tanto por empresas quanto por autônomos. Este tipo de carga em geral possui peso específico de $750 \mathrm{Kg}$ por metro cúbico. Esta informação é importante para determinar o carregamento ao qual o veículo será submetido, uma vez que não se pode ultrapassar o carregamento máximo permitido para cada tipo de veículo. Ainda, verifica-se com base nos dados do IBGE (2012), que são transportadas, mensalmente, pouco mais de 182 mil toneladas de carga seca de São Paulo para o Rio de Janeiro. A Tabela 5 apresenta os dados relativos à carga considerada no estudo.

Tabela 4 - Dados do Veículo Considerado ${ }^{4}$

\begin{tabular}{|c|c|c|}
\hline Especificação & Unidade & Valor \\
\hline \multicolumn{3}{|c|}{ Cavalo Trator Scania - R124GA - 4x2 - 360CV } \\
\hline Peso Bruto Total (PBT) & $\mathrm{T}$ & 39 \\
\hline Peso do Chassi & $\mathrm{T}$ & 5,4 \\
\hline Rendimento & $\mathrm{Km} / 1$ & 2,2 \\
\hline Disponibilidade & $\%$ & 93 \\
\hline Custo de Aquisição & $\mathrm{R} \$$ & $280.000,00$ \\
\hline Vida útil econômica & $\mathrm{Anos}$ & 5 \\
\hline Taxa de Valor residual & $\%$ & $20 \%$ \\
\hline \multicolumn{2}{|c|}{ Semi-reboque graneleiro } \\
\hline Peso semi-reboque & $\mathrm{t}$ & 7,25 \\
\hline Peso de equipamentos & $\mathrm{t}$ & 0,35 \\
\hline Disponibilidade & $\%$ & 93 \\
\hline Custo de aquisição & $\mathrm{R} \$$ & $70.000,00$ \\
\hline Vida útil econômica & anos & 5 \\
\hline Taxa de valor residual & $\%$ & 20 \\
\hline
\end{tabular}

${ }^{4}$ Fonte: Scania (2012). 
Tabela 5 - Dados da Carga Considerada ${ }^{5}$

\begin{tabular}{|c|c|c|}
\hline \multicolumn{3}{|c|}{ Carga geral (carga seca) } \\
\hline Peso específico aproximado & $\mathrm{t} / \mathrm{m}^{3}$ & 0,75 \\
\hline Grau Precisão previsão & $\%$ & 100 \\
\hline Previsão anual (empresas pesquisadas) & $\mathrm{t} / \mathrm{ano}$ & $2.186 .304,00$ \\
\hline Previsão mensal (empresas pesquisadas) & $\mathrm{t} / \mathrm{mês}$ & $182.192,00$ \\
\hline
\end{tabular}

\section{- Dados da Rota}

Segundo dados coletados junto às transportadoras e aos autônomos pesquisados, foi possível levantar as informações necessárias para o planejamento da operação de transporte no eixo considerado pelo estudo. Tais informações são apresentadas na Tabela 6.

\section{Tabela 6 - Dados da Rota Considerada}

\begin{tabular}{|c|c|c|}
\hline \multicolumn{3}{|c|}{ Dados operacionais - São Paulo a Rio de Janeiro } \\
\hline Tempo de carga e descarga (ida) & $\mathrm{h}$ & 5 \\
\hline Tempo de carga e descarga (volta) & $\mathrm{h}$ & - \\
\hline Tempo de espera (RJ) & $\mathrm{h}$ & 3 \\
\hline Distância SP-RJ (ida) & $\mathrm{Km}$ & 440 \\
\hline Distância RJ- SP (volta) & $\mathrm{Km}$ & 440 \\
\hline Velocidade operacional (ida) & $\mathrm{Km} / \mathrm{h}$ & 55 \\
\hline Velocidade operacional (volta) & $\mathrm{Km} / \mathrm{h}$ & 65 \\
\hline Jornada de trabalho & $\mathrm{h}$ & 8 \\
\hline Turnos de trabalho & $\mathrm{Un}$. & 2 \\
\hline Rendimento viagem (8h) & $\mathrm{Km}$ & 650 \\
\hline Dias gastos com retorno & Un. & 6 \\
\hline Dias de manutenção/mês & Un. & 2 \\
\hline Dias de trabalho/mês & Un. & 22 \\
\hline
\end{tabular}

De acordo com informações colhidas nas entrevistas, o tempo médio de carregamento em São Paulo e de descarregamento no Rio de Janeiro é de cerca de 5 horas, sendo que não foi considerada a carga de retorno. Isto ocorre porque muitas vezes não há carga de retorno, uma vez que a carga movimentada na rota inversa é muito inferior à rota normal, o que acaba desestimulando tanto a empresa quanto o autônomo a aguardar pela carga de retorno, pois a mesma pode demorar muito. Portanto, neste estudo, foi considerado o pior cenário que trata do transporte de carga no sentido São Paulo a Rio de Janeiro, retornado vazio. Foi considerado, também, um tempo de espera no Rio de Janeiro para descarregar de 3 horas, pois muitas vezes o veículo chega ao destino e precisa aguardar na fila do centro de distribuição para ser descarregado ou carregado.

\footnotetext{
${ }^{5}$ Fonte: IBGE (2012).
} 
A distância de ida e volta da cidade de São Paulo à cidade do Rio de Janeiro pela Via Dutra são iguais e, segundo DNIT (2012), é de cerca de 440 quilômetros. No trajeto de ida (sentido Rio de Janeiro) a velocidade operacional real, considerando-se paradas, sinais de trânsito, praças de pedágio, congestionamentos em cidades e demais itens que influenciam no andamento do veículo é de aproximadamente $55 \mathrm{Km} / \mathrm{h}$ e na volta, $65 \mathrm{Km} / \mathrm{h}$, pois o mesmo encontra-se vazio, além de ser um trecho de descida da Serra das Araras, possibilitando assim desenvolver maior velocidade.

A jornada de trabalho foi considerada com base na consolidação das leis trabalhistas (CLT), sendo esta de 8 horas diárias em dois turnos de trabalho. Assim, o rendimento diário possível para este veículo é, em média, de $650 \mathrm{Km}$ por dia de trabalho (CNT, 2011).

\section{- Dados da Operação}

Com base nos dados coletados e demonstrados anteriormente tornou-se possível o cálculo da operação de transporte no eixo São Paulo a Rio de Janeiro, ou seja, todos os itens relacionados à movimentação da carga que necessitam ser considerados no planejamento da atividade de transporte, tais como: peso do veículo, carga a ser transportada, número de viagens, tempos, capacidade de transporte, distâncias consideradas, dentre outros. Os resultados são apresentados na Tabela 7.

Observa-se que descontados do peso bruto total do veículo, o peso próprio do cavalo mecânico e do semi-reboque e ainda os equipamentos, a capacidade de carga é de 26 toneladas. Assim, são necessárias pouco mais de 7 mil viagens para atender à demanda mensal de 182.192 toneladas de carga geral no eixo (Tabela 5).

O tempo total de cada viagem é de 16 horas, se somados os tempos de deslocamento e ainda os tempos de carga, descarga e espera, conforme apresentado na Tabela 6. Assim, há a possibilidade de que cada veículo faça 22 viagens por mês nesta rota, o que demanda cerca de 319 veículos para transportar a carga geral considerada. O tempo de retorno, no mês, é de aproximadamente 154 horas, ou seja, cerca de 6 dias por mês são gastos com o retorno do veículo a São Paulo para novo carregamento. 
Tabela 7 - Fluxo Operacional na Rota Considerada

\begin{tabular}{|c|c|c|}
\hline Especificação & Unidade & Valor \\
\hline Peso total do veículo (tara) & $\mathrm{T}$ & 13 \\
\hline Carga útil (lotação) & $\mathrm{T}$ & 26 \\
\hline $\mathrm{N}^{\mathrm{o}}$ viagens mensais & $\mathrm{Un}$. & $7.007,38$ \\
\hline Tempo de viagem (ida) & $\mathrm{H}$ & 8 \\
\hline Tempo de viagem (volta) & $\mathrm{H}$ & 6,77 \\
\hline Tempo total de viagem & $\mathrm{H}$ & 16 \\
\hline Tempo Diário de Operação & $\mathrm{H}$ & 16 \\
\hline $\mathrm{N}^{\mathrm{o}}$ viagens/veículo/dia & $\mathrm{Un}$. & 1 \\
\hline $\mathrm{N}^{\mathrm{o}}$ viagens/veículo/mês & $\mathrm{Un}$. & 22 \\
\hline $\mathrm{N}^{\mathrm{o}}$ veículos frota (calculado) & $\mathrm{Un}$. & 318,52 \\
\hline $\mathrm{N}^{\mathrm{o}}$ veículos frota (considerado) & $\mathrm{Un}$. & 319 \\
\hline $\mathrm{Capacidade} \mathrm{mensal/veic.}^{\text {Capacidade mensal/frota }}$ & $\mathrm{T}$ & 572 \\
\hline Saldo (capac. Frota x demanda carga) & $\mathrm{T}$ & $182.468,00$ \\
\hline Distância média diária/veic. & $\mathrm{Km}$ & 276,00 \\
\hline Distância média mensal/veic. & $\mathrm{Km}$ & 940,00 \\
\hline Distância média anual/veic. & $\mathrm{Km}$ & $116.160,00$ \\
\hline \multicolumn{2}{|c}{} \\
\hline
\end{tabular}

A capacidade de transporte destes 319 veículos somados é $0,15 \%$ maior do que a demanda de carga neste eixo, ou seja, a frota tem uma capacidade excedente disponível de pouco mais de 276 toneladas de carga. Logo, cada veículo tem disponibilidade de desempenhar cerca de 440 quilômetros por dia de operação, o que significará mais de 116 mil quilômetros anuais.

\subsubsection{Cálculo dos custos operacionais}

Uma vez elaborado o fluxo de transporte das cargas a serem transportadas no eixo em questão, tornam-se necessários os cálculos dos custos operacionais envolvidos nesta atividade. Ressalta-se que, para esta análise, foram consideradas três diferentes visões (agentes do sistema): a empresa, o autônomo ideal, caracterizado como o transportador autônomo que tem todos os custos inerentes à profissão e ainda, o autônomo prático, que é aquele que não considera ou não pratica alguns dos custos inerentes ao trabalho, como, por exemplo, o seguro. Desta forma, foi realizada uma pesquisa de mercado dos custos de insumos operacionais básicos dos veículos de transporte rodoviários sob o ponto de vista dos três tipos de transportadores considerados, conforme apresentado na Tabela 8. 
Tabela 8 - Insumos Operacionais Básicos

\begin{tabular}{|l|l|l|l|l|}
\hline Especificação & Unidade & Empresa & Autônomo Ideal & Autônomo prático \\
\hline Preço Diesel & $\mathrm{R} \$ / 1$ & 1,85 & 2,10 & 2,10 \\
\hline Preço do óleo de cárter/litro & $\mathrm{R} \$ / 1$ & 10,50 & 12,50 & 12,50 \\
\hline Custo óleo câmbio/litro & $\mathrm{R} \$ / 1$ & 8,00 & 9,50 & 9,50 \\
\hline Preço do pneu & $\mathrm{R} \$ /$ unidade & $1.102,85$ & $1.575,50$ & $1.575,50$ \\
\hline Câmara & $\mathrm{R} \$$ /unidade & 49,00 & 70,00 & 70,00 \\
\hline Protetor & $\mathrm{R} \$ /$ unidade & 42,00 & 60,00 & 60,00 \\
\hline Custo recapagem a frio & $\mathrm{R} \$ /$ unidade & 315,00 & 450,00 & 413,00 \\
\hline $\begin{array}{l}\text { Manutenção (taxa sobre } \\
\text { o valor do veículo) }\end{array}$ & $\%$ & $1,5 \%$ & $1,5 \%$ & $2,5 \%$ \\
\hline Custo lavagem e engraxamento & $\mathrm{R} \$$ /unidade & 91,00 & 130,00 & 130,00 \\
\hline Preço do pedágio SP-RJ/RJ-SP & $\mathrm{R} \$ /$ unidade & 376,00 & 376,00 & 376,00 \\
\hline
\end{tabular}

Observa-se, por meio da Tabela 8, que os preços dos insumos são maiores para os dois tipos de autônomos, sendo ainda pior para o autônomo prático. A maior parte destes descontos nos custos de aquisição de insumos para as empresas se deve ao fato das mesmas adquirirem produtos em grande quantidade e fecharem grandes contratos com fornecedores de peças e equipamentos, o que lhes garantem boas argumentações nas negociações de redução de custos. Os autônomos, por adquirirem produtos individualizados ou em pequenas quantidades, não conseguem os mesmos descontos. Destaca-se também que a taxa de manutenção para o autônomo ideal permanece igual à empresa. Porém, para o autônomo prático, é considerada $1 \%$ maior devido à idade avançada do veículo, o que requer maiores gastos com manutenções sucessivas. Ainda, conforme apresentado na Seção 5.1.1, foi considerado, neste estudo, o veículo carreta 3 eixos. Os dados sobre o veículo para os três tipos de transportadores considerados, obtidos a partir de pesquisa do mercado, são apresentados na Tabela 9.

Observa-se que o autônomo ideal acaba pagando o preço total do veículo, enquanto a empresa consegue um desconto de $15 \%$. Para o autônomo prático, foi considerada a aquisição de um veículo usado, mas em bom estado de conservação, que custa em média $50 \%$ ou menos do valor de um novo (Scania, 2012). Também foi considerada a aquisição de pneus para completar o conjunto rodante do veículo, uma vez que este não vem completo de fábrica. Quando se adquire uma carreta 3 eixos nova, esta vem com apenas 8 pneus dos 20 necessários, sendo, portanto preciso adquirir os outros 12 pneus restantes. Estes custos são diferentes entre os cenários e proporcionais aos preços apresentados na Tabela 9. 
Tabela 9 - Custos do Veículo ${ }^{6}$

\begin{tabular}{|l|l|l|l|l|}
\hline Custos & Unidade & Empresa & $\begin{array}{l}\text { Autônomo } \\
\text { Ideal }\end{array}$ & $\begin{array}{l}\text { Autônomo } \\
\text { prático }\end{array}$ \\
\hline $\begin{array}{l}\text { Cavalo trator Scania R124GA 4x2 } \\
\text { 360 CV }\end{array}$ & $\mathrm{R} \$$ & $238.000,00$ & $280.000,00$ & $140.000,00$ \\
\hline $\begin{array}{l}\text { Semi-reboque } \\
\text { furgão/alumínio }\end{array}$ & $\mathrm{R} \$$ & $59.500,00$ & $70.000,00$ & $35.000,00$ \\
\hline Pneumáticos (12) eixos & $\mathrm{R} \$$ & $13.234,20$ & $18.906,00$ & $9.453,00$ \\
\hline Sistema rodoar & $\mathrm{R} \$$ & $1.275,00$ & $1.500,00$ & 750,00 \\
\hline Custo total da unidade & $\mathrm{R} \$$ & $310.734,20$ & $368.906,00$ & $184.453,00$ \\
\hline
\end{tabular}

Outro item de custo é o sistema rodoar, pois, atualmente os veículos utilizam este sistema de auxílio à calibragem dos pneus que, além de mantê-los com a calibragem correta, contribuem para uma direção mais segura e para o aumento da vida útil dos pneus. Este sistema possui diferenças nos preços de aquisição entre os cenários, ficando cerca de $15 \%$ mais barato para a empresa. Ressalta-se que apesar do autônomo prático adquirir o veículo usado, e este já vir com os pneus e o sistema rodoar, sempre há a necessidade de trocas ou recapagens de pneus e manutenções no sistema. Deste modo, foi previsto um valor de cerca de $50 \%$ dos gastos do veículo novo, a fim que possam ser efetuados estes acertos necessários ao início da operação do veículo.

Portanto, com base nos dados levantados sobre os insumos operacionais básicos (Tabela 8) e sobre o veículo (Tabela 9), foram realizados os cálculos dos custos operacionais. Estes cálculos foram divididos em três grandes grupos: despesas operacionais (compostas basicamente pelas despesas diretas e despesas indiretas), lucro operacional e os impostos e taxas. As despesas diretas, por sua vez, se dividem em custos fixos e custos variáveis, já as despesas indiretas se dividem em salários e encargos sociais e outras despesas, as quais serão apresentadas a seguir.

\footnotetext{
${ }^{6}$ Fonte: Scania (2012).
} 
Tabela 10 - Custos Fixos

\begin{tabular}{|c|c|c|c|c|}
\hline \multicolumn{5}{|c|}{ CUSTOS OPERACIONAIS } \\
\hline ESPECIFICAÇÃO & Unidade & Empresa & $\begin{array}{r}\text { Autônomo } \\
\text { (ideal) }\end{array}$ & $\begin{array}{r}\text { Autônomo } \\
\text { (prático) }\end{array}$ \\
\hline \multicolumn{5}{|l|}{1 - DESPESAS DIRETAS } \\
\hline \multicolumn{5}{|l|}{ 1.1 - Custos Fixos } \\
\hline \multicolumn{5}{|l|}{ 1.1.1 - Remuneração do Capital (RC) } \\
\hline Capital Empatado em Peças de Reposição & $\%$ & $1,5 \%$ & $1,5 \%$ & $0,0 \%$ \\
\hline TMA (taxa mínima de atratividade) & $\%$ & $12,0 \%$ & $12,0 \%$ & $0,0 \%$ \\
\hline Coeficiente & $\%$ & $13,5 \%$ & $13,5 \%$ & $0,0 \%$ \\
\hline Remuneração de Capital/veículo & $\mathrm{R} \$ / \mathrm{mês}$ & 3.496 & 4.150 & 0 \\
\hline Remuneração de Capital/frota & $\mathrm{R} \$ / \mathrm{mês}$ & 1.115 .147 & 1.323 .911 & 0 \\
\hline \multicolumn{5}{|l|}{ 1.1.2 - Salário do Motorista (SM) } \\
\hline Salário Mínimo Brasil (2012) & $\mathrm{R} \$ / \mathrm{mês}$ & 623 & 623 & 623 \\
\hline Salário Médio Motorista & $\mathrm{R} \$ / \mathrm{mês}$ & 1.557 & 1.557 & 1.557 \\
\hline Encargos Sociais e Benefícios & $\%$ & $104,5 \%$ & $11,0 \%$ & $11,0 \%$ \\
\hline Salário e Encargos (p/ motorista) & $\mathrm{R} \$ / \mathrm{mês}$ & 3.183 & 1.728 & 1.728 \\
\hline Motoristas/Veículo & Núm. & 2 & 2 & 1 \\
\hline Salários Motoristas c/ Encargos (p/ veículo) & $\mathrm{R} \$ / \mathrm{mês}$ & 6.366 & 3.456 & 1.728 \\
\hline Salários Motoristas c/ Encargos (frota) & $\mathrm{R} \$ / \mathrm{mês}$ & 2.030 .671 & 1.102 .512 & 551.256 \\
\hline \multicolumn{5}{|l|}{ 1.1.3 - Sálario Oficina Mecânica (SO) } \\
\hline Salário Médio Mecânico & $\mathrm{R} \$ / \mathrm{mês}$ & 934 & 0 & 0 \\
\hline Encargos Sociais e Benefícios & $\%$ & $104,4 \%$ & $11,0 \%$ & $11,0 \%$ \\
\hline Salário e Encargos (p/ mecânico) & $\mathrm{R} \$ / \mathrm{mês}$ & 1.910 & 0 & 0 \\
\hline Mecânico/Veículo (Pesados $=3$, Semipesados $=4$ e Leves $=5$ ) & Núm. & 106 & 106 & 106 \\
\hline Salário Oficina c/ Encargos (p/ frota) & $\mathrm{R} \$ / \mathrm{mês}$ & 203.067 & 0 & 0 \\
\hline \multicolumn{5}{|l|}{ 1.1.4 - Reposição do Veículo (RV) } \\
\hline Valor Residual $($ Residual = 20\% e Depreciação = 80\% $)$ & $\%$ & $20,0 \%$ & $20,0 \%$ & $5,0 \%$ \\
\hline Vida Útil $($ Pesados $=84$, Semipesados $=724$ e Leves $=60)$ & Meses & 60 & 60 & 180 \\
\hline Custo de Reposição (p/ veículo sem pneus) & $\mathrm{R} \$ / \mathrm{mês}$ & 3.173 & 3.733 & 739 \\
\hline Custo de Reposição Total (frota) & $\mathrm{R} \$ / \mathrm{mês}$ & 1.012.293 & 1.190 .933 & 235.706 \\
\hline \multicolumn{5}{|l|}{ 1.1.5 - Reposição do Equipamento (RE) } \\
\hline Valor Residual (Residual = 5\% e e Depreciação = 95\%) & $\%$ & $5,00 \%$ & $5,00 \%$ & $5,00 \%$ \\
\hline Vida Útil $($ Pesados $=84$, Semipesados $=72$ e Leves $=60)$ & Meses & 60 & 60 & 180 \\
\hline Custo de Reposição (p/ equipamento-veículo sem pneus) & $\mathrm{R} \$ / \mathrm{mês}$ & 942 & 1108 & 185 \\
\hline Custo de Reposição Total (frota) & $\mathrm{R} \$ / \mathrm{mês}$ & 300.525 & 353.558 & 58.926 \\
\hline \multicolumn{5}{|c|}{ 1.1.6 - Licenciamento Anual (LC): DPVAT, IPVA e LICENÇA } \\
\hline DPVAT (Categoria 10) & $\mathrm{R} \$$ & 106 & 106 & 106 \\
\hline IPVA (percentual do cavalo trator) & $\%$ & $1,5 \%$ & $1,5 \%$ & $1,5 \%$ \\
\hline Licença (taxa de licenciamento anual) & $\mathrm{R} \$$ & 63 & 63 & 63 \\
\hline Despachante & $\mathrm{R} \$$ & 51 & 60 & 60 \\
\hline Custo Total do Licenciamento (p/ veículo) & $\mathrm{R} \$ / \mathrm{mês}$ & 316 & 369 & 194 \\
\hline Custo Total do Licenciamento (frota) & $\mathrm{R} \$ / \mathrm{mês}$ & 100.734 & 117.721 & 61.896 \\
\hline \multicolumn{5}{|c|}{ 1.1.7 - Seguro do Veículo (SV): Valores Médios de Seguradoras } \\
\hline Custo Total do Seguro (p/ veículo) & $\mathrm{R} \$ / \mathrm{mês}$ & 1.476 & 1.640 & 0 \\
\hline Custo Total do Seguro (frota) & R\$/mês & 470.701 & 523.001 & 0 \\
\hline \multicolumn{5}{|c|}{ 1.1.8 - Seguro do Equipamento (SE): Valores Médios de Seguradoras } \\
\hline Custo Total do Seguro (p/ veículo) & $\mathrm{R} \$ / \mathrm{mês}$ & 319 & 375 & 0 \\
\hline Custo Total do Seguro (frota) & $\mathrm{R} \$ / \mathrm{mês}$ & 101.681 & 119.625 & 0 \\
\hline \multicolumn{5}{|c|}{ 1.1.9 - Responsabilidade Civil Facultativa (RCF): Valores Médios de Seguradoras } \\
\hline Custo Total da Responsabilidade Civil ( $\mathrm{p} /$ veículo) & $\mathrm{R} \$ / \mathrm{mês}$ & 162 & 190 & 0 \\
\hline Custo Total da Responsabilidade Civil (frota) & $\mathrm{R} \$ / \mathrm{mês}$ & 51.596 & 60.701 & 0 \\
\hline \multicolumn{5}{|l|}{ 1.1.10 - Padronização (Pinturas, Adesivos e Logomarca) } \\
\hline Valor da Padronização & $\mathrm{R} \$$ & 3.563 & 0 & 0 \\
\hline Vida útil & Mês & 36 & 36 & 36 \\
\hline Custo da Padronização (p/ veículo) & $\mathrm{R} \$ / \mathrm{mês}$ & 99 & 0 & 0 \\
\hline Custo da Padronização (frota) & $\mathrm{R} \$ / \mathrm{mês}$ & 31.573 & 0 & 0 \\
\hline Subtotal Custos Fixos (frota) & $\mathrm{R} \$ / \mathrm{mês}$ & 5.417 .988 & 4.791 .963 & 907.784 \\
\hline
\end{tabular}




\subsubsection{Despesas Diretas}

São consideradas despesas diretas aquelas relacionadas à operação dos veículos de transporte, as quais estão divididas em custos fixos e variáveis:

\section{- Custos Fixos}

No estudo em questão, são considerados custos fixos todos aqueles que incidem independente do veículo estar ou não operando, ou seja, rodando ou não estes custos deverão ser pagos mensalmente.

Ressalta-se que, para todos os cálculos, foi considerada a frota necessária para o transporte de toda a demanda de carga geral identificada no eixo São Paulo - Rio de Janeiro, conforme apresentado na Seção 5.1.1. A Tabela 10 resume todos os cálculos efetuados para os custos fixos, descritos a seguir.

\section{a) Remuneração do Capital (RC)}

Corresponde ao ganho no mercado financeiro caso o capital não tivesse sido usado para adquirir o veículo. A Equação 1 é utilizada para calcular a remuneração de capital. Destaca-se que o coeficiente 0,135 apresentado na equação corresponde à taxa anual de juros de $12 \%^{7}$ (taxa mínimia de atratividade) mais $1,5 \%$ ao ano relativo à imobilização em peças de reposição (Guia do Transportador, 2012).

$$
R C=\frac{V A L O R_{-} V E I C U L O \_C O M P L E T O * 0,135}{12}
$$

Ressalta-se que para o autônomo prático não se consideram este cálculos, pois isto não faz parte do cotidiano desta classe de trabalhadores. Porém, tais cálculos serão levados em consideração para o autônomo ideal. Assim, a diferença observada entre o autônomo ideal e a empresa se deve aos valores diferentes na aquisição do veículo.

\section{b) Salário do Motorista (SM)}

Corresponde às despesas mensais com salário de motorista e horas extras, acrescidas dos encargos sociais. Foi considerado o salário médio de mercado da região sudeste do Brasil, neste estudo, acrescidos os encargos sociais e benefícios, como: INSS, FGTS, SEST, SENAT,

\footnotetext{
${ }^{7}$ A taxa de $12 \%$ ao ano foi utilizada para cálculos de financiamentos pelo sistema bancário brasileiro no início do ano de 2012 (Guia do Transportador, 2012).
} 
INCRA, SEBRAE, Salário educação, Seguro acidente do trabalho, Férias, 1/3 Férias, Aviso Prévio, Auxílio Doença, Férias Proporcionais (Sobre Aviso), 13 Salário, Vale transporte, Cesta básica e uniforme/EPI. Apesar de grande parte dos autônomos, na prática, não se preocupar em pagar o INSS para futuramente receber o benefício da aposentadoria, alguns o fazem corretamente. Assim, considerou-se neste estudo que mesmo o autônomo prático paga encargos referentes a $11 \%$ sobre o seu salário, como forma de garantir sua aposentadoria.

São considerados dois motoristas por veículo para a empresa e para o autônomo ideal, entretanto, para o autônomo prático é considerado apenas um motorista, pois sabe-se que ele mesmo é quem arca com toda a exaustiva jornada de trabalho.

\section{c) Salário da Oficina Mecânica (SO)}

Corresponde a despesas relacionadas ao pessoal de manutenção e seus encargos sociais. Para os salários da oficina mecânica, foram considerados valores médios praticados na região Sudeste (obtidos a partir de pesquisa de mercado), sendo que apenas a empresa tem custos com oficina, uma vez que ambos os autônomos utilizam serviços terceirizados. Os encargos e benefícios são aplicados de forma semelhantes aos verificados para os motoristas. A quantidade de trabalhadores foi calculada seguindo-se a proporção de 3 mecânicos por veículo pesados, 4 por veículo semi-pesado e 5 por veículo leve, conforme praticado pela empresas transportadoras (NTC, 2001).

\section{d) Reposição do Veículo (RV)}

Corresponde à quantia destinada mensalmente a um fundo para adquirir outro veículo novo quando o atual completar seu ciclo de vida útil econômica do veículo. Para este cálculo utiliza-se a Equação 2. Considera-se que no fim desse período (VV - Vida útil do veículo em meses), o valor de revenda do veículo seja de $20 \%$ do valor do veículo novo (Receita Federal, 2012). Destaca-se que o valor dos pneus, que constituem material de consumo, não é considerado pela Equação 2, pois essa despesa é computada em um item específico do custo variável. 4.

$$
R V=\frac{V A L O R_{-} V E I C U L O_{-} Z E R O_{-} S E M_{-} P N E U S * 0,80}{V V}
$$


Considerou-se no estudo uma depreciação, ao longo de 60 meses, de $80 \%$ do valor inicial do veículo para a empresa e para o autônomo ideal, restando, portanto, 20\% de valor residual, que geralmente é utilizado para o pagamento da parcela inicial do veículo novo (NTC, 2001). Para o autônomo prático, foi considerada uma depreciação de $95 \%$ do valor inicial de aquisição do veículo e um valor residual de $5 \%$ em 180 meses. Isto se deve ao fato de que este último utiliza o veículo até o seu desgaste quase total, o que reduz bastante o valor final de venda do mesmo.

\section{e) Reposição do Equipamento (RE)}

É considerado da mesma forma do item anterior, no entanto, refere-se à reposição do equipamento rodoviário, que compreende basicamente o semi-reboque, as lonas, cordas de amarração e a estrutura de armação da lona. No final da vida útil econômica do equipamento (VE - Vida útil do equipamento em meses), seu valor de revenda é de apenas $5 \%$ do valor do equipamento novo, considerando a vida útil de 60 meses para a empresa e autônomo ideal (Receita Federal, 2012). Entretanto, foi considerado que o autônomo prático permanece com o equipamento por 180 meses, pelos mesmos motivos anteriormente explicados no item reposição do veículo. A Equação 3 é utilizada para calcular a reposição do equipamento.

$$
R E=\frac{V A L O R_{-} E Q U I P A M E N T O_{-} Z E R O_{-} S E M M_{-} P N E U S * 0,95}{V E}
$$

\section{f) Licenciamento Anual (LC)}

Esse item, calculado a partir da Equação 4, reúne os tributos fiscais que a empresa deve recolher antes de colocar o veículo em circulação nas vias públicas, tais como: Imposto sobre a propriedade de veículos automotores (IPVA); Seguro por danos pessoais causados por veículos automotores (DPVAT); e Taxa de Licenciamento (TL) pago ao DETRAN.

$$
L C=\frac{D P V A T+I P V A+T L}{12}
$$

No licenciamento anual, foram considerados praticamente os mesmos custos unitários e índices de cálculos para todos os cenários. As principais diferenças ficaram por conta do valor pago ao despachante, onde a empresa consegue descontos, e no valor final do licenciamento, pois o IPVA incide sobre o valor do veículo. 


\section{g) Seguro do Veículo (SV)}

Este item foi cotado junto a quatro corretoras de seguros (Sul América, Porto Seguro, Azul Seguros e Itaú Seguros), uma vez que seu cálculo requer várias informações indisponíveis no estudo. Tais informações compreendem: idade do condutor, endereço residencial, envolvimento em acidentes anteriores, quantidade de pontos na carteira de habilitação, tipo de utilização dada ao veículo, local de pernoite do veículo, itens de segurança (trava, alarme, sistema antifurto, etc.), quantos condutores utilizam o veículo e suas idades, dentre outras (Porto Seguro, 2012).

De acordo com Porto Seguro (2012), todos estes dados são inseridos em um software específico que calcula a probabilidade de haver sinistro, ou seja, danos ou perdas ao veículo e com base nesta probabilidade estabelece o valor da apólice a ser paga. Deste modo, pela indisponibilidade de acesso a este software ou mecanismo de cálculo similar, optou-se por estabelecer um condutor padrão médio, semelhante aos entrevistados durante as pesquisas de campo, e solicitar às corretoras que fizessem as cotações do seguro para o veículo nos três cenários diferentes. Assim, foi realizada a cotação junto às quatro seguradoras que trabalham em São Paulo e no Rio de Janeiro com seguros de veículos de carga, e tomou-se como referência a média dos valores apresentados por elas.

\section{h) Seguro do Equipamento (SE)}

Representa a parcela mensal destinada ao pagamento do seguro ou para eventuais sinistros (colisão, incêndio, roubo etc.) ocorridos com o equipamento. Para este item, foram adotados os mesmos critérios do cálculo do seguro veicular, sendo o valor cotado junto às corretoras de seguros. Adotou-se a média dos valores apresentados.

\section{i) Responsabilidade Civil Facultativa (RCF)}

É destinado a cobrir danos materiais e a complementar os danos pessoais causados a terceiros, pois o valor da cobertura do seguro DPVAT é bastante limitado.Este item também foi cotado junto à corretora de seguros, sendo estabelecido que fossem ressarcidos danos pessoais no valor de até $\mathrm{R} \$ 1.578 .87$ e danos materiais $\mathrm{R} \$ 704,55$. 


\section{j) Padronização}

Este item se refere aos custos inerentes às pinturas, adesivos e logomarcas que precisam ser colocados no veículo de forma divulgar o nome do transportador, seja ele empresa ou autônomo. Entretanto, no estudo foi considerado apenas a padronização do veículo da empresa, e seu custo foi cotado junto à empresa especializada neste tipo de atividade.

\section{- Custos Variáveis}

São considerados custos variáveis todos aqueles que incidem apenas quando o veículo se encontra em operação, ou seja, somente quando o veículo está rodando, e o seu cálculo é feito por quilômetro. A Tabela 11 apresenta os resultados obtidos a partir do cálculo dos custos variáveis.

\section{a) Peças, Acessórios e Material de Manutenção (PM)}

Este item se refere a gastos com aquisição de peças e acessórios necessários à manutenção do veículo, sendo estimada a partir de um percentual sobre o valor do veículo novo completo e sem pneus (1,5\% para as empresas transportadoras e o autônomo ideal e de 2,5\% para o autônomo prático). Ressalta-se que, para o autônomo prático, este índice é maior, devido à maior idade do veículo, o que se traduz em maiores gastos com a manutenção. Uma vez apuradas, essas despesas devem ser divididas pela quilometragem mensal percorrida, para se obter um valor por quilômetro.

\section{b) Combustíveis (DC)}

São despesas com combustível para cada quilômetro rodado pelo veículo. Os custos de aquisição do combustível pelos autônomos são maiores do que pela empresa, devido aos grandes volumes adquiridos por esta última.

Para o autônomo prático, também deve ser considerado um maior consumo de combustível (2,0 Km/l para o autônomo prático e $2,2 \mathrm{Km} / 1$ para a empresa transportadora e autônomo ideal), pois veículos mais antigos ou muito usados aumentam gradativamente seu consumo devido ao maior desgaste, fazendo com que os gastos com este insumo sejam bastante onerosos para esta atividade. 
Tabela 11 - Custos Variáveis

\begin{tabular}{|c|c|c|c|c|}
\hline ESPECIFICAÇÃO & Unidade & Empresa & $\begin{array}{r}\text { Autônomo } \\
\text { (ideal) }\end{array}$ & $\begin{array}{r}\text { Autônomo } \\
\text { (prático) }\end{array}$ \\
\hline \multicolumn{5}{|l|}{1.2 - Custos Variáve is } \\
\hline \multicolumn{5}{|c|}{ 1.2.1 - Peças, Acessorios e Material de Manutenção (PM) } \\
\hline Coeficiente & $\%$ & $1,5 \%$ & $1,5 \%$ & $2,5 \%$ \\
\hline Custo Manutenção (p/ veículo) & $\mathrm{R} \$ / \mathrm{km}$ & 0,46 & 0,54 & 0,45 \\
\hline Custo Manutenção (frota) & $\mathrm{R} \$ / \mathrm{km}$ & 147,06 & 173,01 & 144,18 \\
\hline \multicolumn{5}{|l|}{ 1.2.2 - Combustível (DC) } \\
\hline Rendimento & $\mathrm{Km} / \mathrm{l}$ & 2,2 & 2,2 & 2 \\
\hline Custo do Diesel (p/ veículo) & $\mathrm{R} \$ / \mathrm{km}$ & 0,84 & 0,95 & 1,05 \\
\hline Custo do Diesel (frota) & $\mathrm{R} \$ / \mathrm{km}$ & 267,89 & 304,5 & 334,95 \\
\hline \multicolumn{5}{|l|}{ 1.2.3 - Lubrificantes do Motor (LM) } \\
\hline Quilometragem de Troca (média brasileira) & $\mathrm{Km}$ & 15.000 & 15.000 & 15.000 \\
\hline Volume do Cárter & 1 & 25 & 25 & 25 \\
\hline Quilometragem de Reposição & $\mathrm{Km}$ & 1.000 & 1.000 & 500 \\
\hline Taxa de Reposição & 1 & 3 & 3 & 4 \\
\hline Custo do Óleo Cárter (p/ veículo) & $\mathrm{R} \$ / \mathrm{km}$ & 0,05 & 0,06 & 0,12 \\
\hline Custo do Óleo Cárter (frota) & $\mathrm{R} \$ / \mathrm{km}$ & 15,63 & 18,61 & 38,55 \\
\hline \multicolumn{5}{|l|}{ 1.2.4 - Lubrificantes da Transmissão (LT) } \\
\hline Quilometragem de Troca (média brasileira) & $\mathrm{Km}$ & 25.000 & 25.000 & 25.000 \\
\hline Volume do Câmbio e Diferencial & 1 & 30 & 30 & 30 \\
\hline Custo do Óleo Câmbio e Diferencial (p/ veículo) & $\mathrm{R} \$ / \mathrm{km}$ & 0,01 & 0,01 & 0,01 \\
\hline Custo do O. Câmbio/Difer.(Frota) & $\mathrm{R} \$ / \mathrm{km}$ & 3,06 & 3,64 & 3,64 \\
\hline \multicolumn{5}{|l|}{ 1.2.5 - Lavagem e Engraxamento (LG) } \\
\hline Quilometragem Recomendada & $\mathrm{Km}$ & 5.000 & 5.000 & 5.000 \\
\hline Custo L e E (p/ veículo) & $\mathrm{R} \$ / \mathrm{km}$ & 0,02 & 0,03 & 0,03 \\
\hline Custo L e E (frota) & $\mathrm{R} \$ / \mathrm{km}$ & 5,81 & 8,29 & 8,29 \\
\hline \multicolumn{5}{|l|}{ 1.2.6 - Pneus e Recauchutagem (PR) } \\
\hline Coeficiente de Perdas de Carcaças & $\%$ & $20,00 \%$ & $20,00 \%$ & $20,00 \%$ \\
\hline Vida Util do Pneu (c/ 1 recapagem) & $\mathrm{Km}$ & 160.000 & 160.000 & 160.000 \\
\hline Custo de Pneus (p/ veículo) & $\mathrm{R} \$ / \mathrm{km}$ & 0,22 & 0,31 & 0,31 \\
\hline Custo de Pneus (Frota) & $\mathrm{R} \$ / \mathrm{km}$ & 69,69 & 99,55 & 98,08 \\
\hline \multicolumn{5}{|l|}{ 1.2.7 - Pedágios (PD) } \\
\hline Custo do Pedágio (p/ veículo) & $\mathrm{R} \$ / \mathrm{km}$ & 0,43 & 0,85 & 0,85 \\
\hline Custo do Pedágio (frota) & $\mathrm{R} \$ / \mathrm{km}$ & 136,3 & 272,6 & 272,6 \\
\hline Subtotal Custos Variáveis (frota) & $\mathrm{R} \$ / \mathrm{Km}$ & 645,43 & 880,2 & 900,28 \\
\hline
\end{tabular}

\section{c) Lubrificantes do Motor (LM)}

Para calcular as despesas com a lubrificação interna do motor (LM), é utilizada a Equação 5, onde além da reposição total do óleo, também é considerada uma taxa de reposição a cada $1.000 \mathrm{~km}$. 


$$
L M=P L M *\left(\frac{V C}{Q M}+\frac{V R}{1000}\right)
$$

Onde: $P L M=$ Preço unitário do lubrificante do motor $(\mathrm{R} \$ /$ litro $)$

$V C=$ Volume do cárter (litros)

$Q M=$ Quilometragem de troca de óleo do motor

$V R=$ Taxa de reposição (litros/1000 km)

Este item apresenta uma grande diferença entre os custos de aquisição pela empresa e pelos autônomos. Além disto, os veículos dos autônomos práticos, por serem mais antigos ou muitos utilizados, muitas vezes acabam necessitando de trocas de óleo mais freqüentes, o que acarreta maiores custos finais deste item. Outro detalhe importante é que, entre as trocas de óleo previstas, há a necessidade de se verificar o nível do óleo lubrificante e, se houver a necessidade completá-lo. Esta taxa de reposição é maior nos autônomos práticos devido aos motores dos veículos serem mais desgastados e baixarem o nível do óleo com maior frequiência.

\section{d) Lubrificantes da Transmissão (LT)}

Para calcular as despesas realizadas com lubrificação da transmissão do veículo (diferencial e câmbio), é utilizada a Equação 6.

$$
L T=\frac{(V D+V C C) * P L T}{Q T}
$$

Onde: $V D=$ Capacidade da caixa e diferencial (litros)

$V C C=$ Capacidade do Câmbio (litros)

$P L T=$ Preço unitário do lubrificante da transmissão (R $\$ /$ litro)

$Q T=$ Quilometragem de troca da transmissão

Neste item, os custos de aquisição possuem diferença significativa. Entretanto, para o autônomo prático novamente o problema incide na idade do veículo, que o obriga a realizar trocas de óleo sucessivas e com maior freqüência, o que acaba onerando este item. 


\section{e) Lavagem e Engraxamento (LG)}

Neste item, a grande diferença está no fato de que a empresa possui em sua oficina de manutenção e nos centros de distribuição, toda uma estrutura de lavagem e lubrificação para ser utilizada em sua frota. Já os autônomos precisam pagar por este serviço em postos de combustíveis ou empresas especializadas, que acabam cobrando mais caro pelo serviço.

\section{f) Pneus e Recauchutagem (PR)}

A partir de dados levantados em entrevistas com transportadoras e autônomos, considerou-se, para este item, custos de aquisição cerca de $43 \%$ maiores para os autônomos em relação à empresa. Entretanto, um ponto que merece destaque é a grande perda de carcaças de pneus por parte do autônomo prático. Este fato se deve pelo uso demasiado dos pneus, fazendo com que estes muitas vezes não sejam passíveis de reaproveitamento para recauchutagem. Adiciona-se a isto a falta de alinhamento e balanceamento dos pneus que aumentam os índices de perdas ou ainda, os pequenos incidentes que ocasionam perdas de pneus como quedas em buracos, pedras, depressões no asfalto, objetos cortantes e demais problemas que fazem parte do cotidiano da operação de transporte.

\section{g) Pedágios (PD)}

Neste item foram considerados os pedágios que devem ser pagos na Rodovia Presidente Dutra no trecho São Paulo a Rio de Janeiro, que totalizam 6 praças de pedágio. Estes pedágios precisam ser pagos tato na ida quanto na volta e possuem os seguintes valores: $R \$ 9,6 ; R \$ 4,2$; $\mathrm{R} \$ 2,3 ; \mathrm{R} \$ 2,3 ; \mathrm{R} \$ 9,6$ e $\mathrm{R} \$ 9,6$, segundo ANTT (2012).

\subsubsection{Despesas Indiretas}

As despesas diretas são aquelas relacionadas à operação da estrutura administrativa e centros de distribuição da empresa de transporte, correspondendo a: (i) Salários e Encargos Sociais; e (ii) Outras Despesas.

Os salários e encargos pagos aos profissionais envolvidos na operação indireta de transporte, tais como diretoria, secretarias, profissionais de logística e outros. Tais dados, apresentados na Tabela 12, foram obtidos a partir de pesquisas de mercado realizada por entrevistas com empresas e transportadores autônomos. 
Tabela 12 - Salários e Encargos Sociais

\begin{tabular}{|c|c|c|c|c|}
\hline ESPECIFICAÇÃ̃O & Unidade & Empresa & $\begin{array}{l}\text { Autônomo } \\
\text { (ideal) }\end{array}$ & $\begin{array}{r}\text { Autônomo } \\
\text { (prático) }\end{array}$ \\
\hline \multicolumn{5}{|l|}{2 - DESPESA INDIRETAS } \\
\hline \multicolumn{5}{|l|}{2.1 - Salário e Encargos Sociais } \\
\hline \multicolumn{5}{|l|}{ 2.1.1 - Salários, Ordenados e Honorários de Diretoria } \\
\hline Salário Médio Diretores & $\mathrm{R} \$ / \mathrm{mês}$ & 15.568 & 15.568 & 15.568 \\
\hline Encargos Sociais e Benefícios & $\%$ & $104,40 \%$ & $11,00 \%$ & $11,00 \%$ \\
\hline Salário e Encargos (p/ diretor) & $\mathrm{R} \$ / \mathrm{mês}$ & 31.829 & 17.281 & 17.281 \\
\hline $\mathrm{N}^{\mathrm{o}}$ de Diretores & Núm. & 4 & 0 & 0 \\
\hline Salário dos Diretores & $\mathrm{R} \$ / \mathrm{mês}$ & 127.315 & 0 & 0 \\
\hline \multicolumn{5}{|l|}{ 2.1.2 - Salários Profissionais de Escritório e Operação CD } \\
\hline Salário Médio Secretária, Supervisores, Conferentes, técnicose outros & $\mathrm{R} \$ / \mathrm{mês}$ & 2.491 & 2.491 & 2.491 \\
\hline Encargos Sociais e Benefícios & $\%$ & $104,40 \%$ & $11,00 \%$ & $11,00 \%$ \\
\hline Salário e Encargos (p/ profissional) & $\mathrm{R} \$ / \mathrm{mês}$ & 5.093 & 2.765 & 2.765 \\
\hline $\mathrm{N}^{\mathrm{o}}$ de Profissionais & Núm. & 25 & 0 & 0 \\
\hline Salário dos Profissionais & $\mathrm{R} \$ / \mathrm{mês}$ & 127.315 & 0 & 0 \\
\hline Salário Médio Profissional de Logística, Coordenador e Analista & $\mathrm{R} \$ / \mathrm{mês}$ & 8.095 & 8.095 & 8.095 \\
\hline Encargos Sociais e Benefícios & $\%$ & $104,40 \%$ & $11,00 \%$ & $11,00 \%$ \\
\hline Salário e Encargos (p/ profissional) & $\mathrm{R} \$ / \mathrm{mês}$ & 16.551 & 8.986 & 8.986 \\
\hline $\mathrm{N}^{\mathrm{o}}$ de Profissionais de Logística & Núm. & 12 & 0 & 0 \\
\hline Salário dos Profissionais de Logística & $\mathrm{R} \$ / \mathrm{mês}$ & 198.611 & 0 & 0 \\
\hline Salário dos Profissionais do Escritório e CD & $\mathrm{R} \$ / \mathrm{mês}$ & 325.926 & 0 & 0 \\
\hline Subtotal Salários e Encargos & $\mathrm{R} \$ / \mathrm{mês}$ & 453.241 & 0 & 0 \\
\hline
\end{tabular}

As demais despesas necessárias à operação de transporte (outras despesas) são apresentadas na Tabela 13 e correspondem a: aluguéis, tarifa de serviços públicos, serviços profissionais, depreciações e outros custos diversos.

\section{a) Aluguéis}

Este item é considerado apenas para a empresa e corresponde ao preço médio de dois galpões de cerca de $4.000 \mathrm{~m}^{2}$ na região da periferia da cidade de São Paulo e Rio de Janeiro, onde o acesso às rodovias é mais facilitado. Adiciona-se ao valor deste aluguel de imóvel, o aluguel de equipamentos, a saber: 4 empilhadeiras, 1 gerador de energia e 1 veículo de apoio. Estes dados são o valor médio obtido em pesquisa de mercado, a partir de entrevistas com transportadoras que atuam no eixo estudado. 
Tabela 13 - Outras Despesas

\begin{tabular}{|c|c|c|c|c|}
\hline ESPECIFICAÇÃO & Unidade & Empresa & $\begin{array}{r}\text { Autônomo } \\
\text { (ideal) }\end{array}$ & $\begin{array}{r}\text { Autônomo } \\
\text { (prático) }\end{array}$ \\
\hline \multicolumn{5}{|l|}{2.1 - Outras Despesas } \\
\hline \multicolumn{5}{|l|}{ 2.1.1 - Aluguéis } \\
\hline Aluguéis de Áreas e Imóveis & $\mathrm{R} \$ / \mathrm{mês}$ & 30.000 & 0 & 0 \\
\hline Aluguéis de Equipamentos & $\mathrm{R} \$ /$ mês & 24.000 & 0 & 0 \\
\hline Custo de Aluguéis & $\mathrm{R} \$ / \mathrm{t}$ & 0,3 & 0 & 0 \\
\hline \multicolumn{5}{|l|}{ 2.1.2 - Tarifa de Serviços Públicos } \\
\hline Água & $\mathrm{R} \$ / \mathrm{mês}$ & 4.000 & 0 & 0 \\
\hline Energia Elétrica & $\mathrm{R} \$ / \mathrm{mês}$ & 7.000 & 0 & 0 \\
\hline Correios e Courriers & $\mathrm{R} \$ / \mathrm{mês}$ & 4.000 & 0 & 0 \\
\hline Telefone (fixo, celular e rádios) & $\mathrm{R} \$ / \mathrm{mês}$ & 102.080 & 127.600 & 63.800 \\
\hline Internet & $\mathrm{R} \$ / \mathrm{mês}$ & 3.000 & 0 & 0 \\
\hline Custo de Serviços Públicos & $\mathrm{R} \$ / \mathrm{t}$ & 0,66 & 0,7 & 0,35 \\
\hline \multicolumn{5}{|l|}{ 2.1.3 - Serviços Profissionais Terceirizados } \\
\hline Serviços de Manutenção, Conservação e Limpeza & $\mathrm{R} \$ / \mathrm{mês}$ & 15.702 & 0 & 0 \\
\hline Serviços de Vigilância & $\mathrm{R} \$ / \mathrm{mês}$ & 19.873 & 9.936 & 15.950 \\
\hline Serviços de Processamento de Dados & $\mathrm{R} \$ / \mathrm{mês}$ & 11.929 & 0 & 0 \\
\hline Serviços de Atendimento ao Cliente (SAC) & $\mathrm{R} \$ / \mathrm{mês}$ & 11.776 & 0 & 0 \\
\hline Serviço de Rastreamento por Satélite & R\$/mês & 25.201 & 25.201 & 0 \\
\hline Serviço de Escolta Armada e Gerenciamento de Risco & $\mathrm{R} \$ / \mathrm{mês}$ & 3.628 .306 & 1.088 .492 & 0 \\
\hline Serviço de Oficina Mecânica (mão de obra) & $\mathrm{R} \$ / \mathrm{mês}$ & 0 & 1.765 .215 & 1.471 .013 \\
\hline Agenciador de Frete & $\mathrm{R} \$ / \mathrm{mês}$ & 0 & 891.075 & 668.307 \\
\hline Custo de Serviços Terceirizados & $\mathrm{R} \$ / \mathrm{t}$ & 20,38 & 20,75 & 11,83 \\
\hline \multicolumn{5}{|l|}{ 2.1.4 - Depreciações } \\
\hline Depreciação de Máquinas e Equipamentos & $\mathrm{R} \$ / \mathrm{mês}$ & 9.110 & 0 & 0 \\
\hline Depreciação de Móveis e Utensilios & $\mathrm{R} \$ / \mathrm{mês}$ & 9.110 & 0 & 0 \\
\hline Custo de Depreciações & $\mathrm{R} \$ / \mathrm{t}$ & 0,1 & 0 & 0 \\
\hline \multicolumn{5}{|l|}{ 2.1.5 - Outros Custos Diversos } \\
\hline Material de Escritório e Limpeza & $\mathrm{R} \$ / \mathrm{mês}$ & 9.110 & 0 & 0 \\
\hline Viagens, Estadias e Condução & $\mathrm{R} \$ / \mathrm{mês}$ & 7.288 & 0 & 0 \\
\hline Despesas Legais e Judiciais & $\mathrm{R} \$ / \mathrm{mês}$ & 14.575 & 0 & 0 \\
\hline Contribuições e Doações & $\mathrm{R} \$ / \mathrm{mês}$ & 15.000 & 0 & 0 \\
\hline Uniformes & $\mathrm{R} \$ / \mathrm{mês}$ & 23.560 & 0 & 0 \\
\hline Despesas (promoções, brindes e propaganda) & R\$/mês & 5.466 & 0 & 0 \\
\hline Despesas (conservação de bens e instalações) & $\mathrm{R} \$ / \mathrm{mês}$ & 3.000 & 0 & 0 \\
\hline Despesas Diversas & $\mathrm{R} \$ / \mathrm{mês}$ & 18.219 & 18.219 & 18.219 \\
\hline Refeições e Lanches & $\mathrm{R} \$ / \mathrm{mês}$ & 140.360 & 280.720 & 357.280 \\
\hline Cópias Xerox & $\mathrm{R} \$ / \mathrm{mês}$ & 3.644 & 0 & 0 \\
\hline Paletização/conteinerização de Cargas & R\$/mês & 91.096 & 0 & 0 \\
\hline IPTU - Imposto Predial Territorial Urbano & $\mathrm{R} \$ / \mathrm{mês}$ & 750 & 0 & 0 \\
\hline Custo dos Diversos & $\mathrm{R} \$ / \mathrm{t}$ & 1,82 & 1,64 & 2,06 \\
\hline Subtotal Outras Despesas & $\mathrm{R} \$ / \mathrm{t}$ & 23,26 & 23,09 & 14,24 \\
\hline Subtotal Outras Despesas & $\mathrm{R} \$ / \mathrm{mês}$ & 4.237 .153 & 4.206 .459 & 2.594 .568 \\
\hline
\end{tabular}




\section{b) Tarifa de Serviços Públicos}

Neste item, estão considerados os custos com serviços básicos necessários à operação. Salienta-se que apenas os gastos com telefone é comum aos três cenários considerados no estudo, sendo os demais pertinentes apenas à empresa.

\section{c) Serviços de Profissionais Terceirizados}

Alguns serviços essenciais ao bom funcionamento das atividades que viabilizam as operações de transporte precisam ser contratados externamente por meio da terceirização de serviços. Deste modo, este item trata destes serviços que são imprescindíveis tanto para a empresa, quanto para os autônomos, são imprescindíveis. Salienta-se, no entanto, que nem todos os serviços são comuns aos três cenários considerados, como pode ser verificado na Tabela 13.

\section{d) Depreciações}

São considerados todos os custos relativos às depreciações de maquinários, equipamentos, móveis e utensílios utilizados no centro de distribuição da empresa, visto que os autônomos não possuem estes custos.

\section{e) Outros Custos Diversos}

Neste item, são descritas todas as despesas diversas e que não foram contabilizadas nos outros itens anteriores, mas que são importantes para o funcionamento indireto da operação de transporte de carga.

\subsubsection{Lucro Operacional}

O lucro operacional foi estabelecido com base no que foi observado como prática geral no mercado de fretes rodoviários de cargas. Tendo como referência as empresas de transporte pesquisadas, pode-se constatar que as mesmas arbitram um percentual de $10 \%$ a ser aplicado sobre os custos operacionais, depois da incidência dos impostos. Deste modo, utilizou-se este percentual nos cálculos dos custos do frete rodoviário para os três cenários do estudo.

\subsubsection{Impostos e Taxas}

Trata-se de toda a carga tributária que incide sobre os custos de operação de transporte, conforme a legislação contábil em vigor. A Tabela 14 apresenta os impostos pagos pela operação de transporte. 


\begin{tabular}{|c|c|c|c|c|}
\hline ESPECIFICAÇÃO & Unidade & Empresa & $\begin{array}{r}\text { Autônomo } \\
\text { (ideal) }\end{array}$ & $\begin{array}{r}\text { Autônomo } \\
\text { (prático) }\end{array}$ \\
\hline \multicolumn{5}{|l|}{2 - Impostos e Taxas } \\
\hline PIS & $\mathrm{R} \$ / \mathrm{mês}$ & 107.011 & 0 & 0 \\
\hline COFINS & $\mathrm{R} \$ / \mathrm{mês}$ & 505.861 & 0 & 0 \\
\hline CSLL & $\mathrm{R} \$ / \mathrm{mês}$ & 471.165 & 0 & 0 \\
\hline ICMS & $\mathrm{R} \$ / \mathrm{mês}$ & 1.784 .310 & 0 & 0 \\
\hline IR & $\mathrm{R} \$ / \mathrm{mês}$ & 824.681 & 0 & 0 \\
\hline Total de Impostos e Taxas & $\mathrm{R} \$ / \mathrm{mês}$ & 3.693 .028 & 0 & 0 \\
\hline Subtotal Despesas (com impostos e taxas) & $\mathrm{R} \$ / \mathrm{mês}$ & 20.049 .199 & 17.518 .780 & 12.217 .055 \\
\hline
\end{tabular}

\subsubsection{Custos Operacionais Resultantes}

A Tabela 15 sintetiza os resultados obtidos por meio dos cálculos relativos à atividade de transporte de carga geral no eixo São Paulo - Rio de Janeiro, apresentando as despesas operacionais resultantes desta operação.

Tabela 15 - Detalhamento das Despesas Operacionais

\begin{tabular}{|c|c|c|c|c|}
\hline \multicolumn{2}{|l|}{ Resumo dos Custos } & \multirow{2}{*}{$\begin{array}{r}\text { Empresa } \\
11.665 .777\end{array}$} & \multirow{2}{*}{$\begin{array}{r}\begin{array}{r}\text { Autônomo } \\
\text { (ideal) }\end{array} \\
13.312 .321\end{array}$} & \multirow{2}{*}{$\begin{array}{r}\begin{array}{r}\text { Autônomo } \\
\text { (prático) }\end{array} \\
\mathbf{9 . 6 2 2 . 4 8 6}\end{array}$} \\
\hline Despesas Diretas & & & & \\
\hline Custos Fixos & $\mathrm{R} \$ / \mathrm{mês}$ & 5.417 .988 & 4.791 .963 & 907.784 \\
\hline Custos Variáveis & $\mathrm{R} \$ / \mathrm{mês}$ & 6.247 .789 & 8.520 .358 & 8.714 .702 \\
\hline Despesas Indiretas & & 4.690 .393 & 4.206 .459 & 2.594 .568 \\
\hline Salários e Encargos Sociais & $\mathrm{R} \$ / \mathrm{mês}$ & 453.241 & 0 & 0 \\
\hline Outras Despesas & $\mathrm{R} \$ / \mathrm{mês}$ & 4.237 .153 & 4.206.459 & 2.594 .568 \\
\hline Imposto e Taxas & R\$/mês & 3.693.027 & 0 & $\mathbf{0}$ \\
\hline Lucro Operacional & $\mathbf{R} \$ / \mathbf{m e ̂ s}$ & 2.227 .689 & 1.946 .531 & 1.357 .451 \\
\hline Custo Ope racional Total & $\mathbf{R} \mathbf{R}$ & 22.276 .886 & 19.465.311 & 13.574.505 \\
\hline
\end{tabular}

A partir das despesas operacionais, chega-se ao preço final da operação de transporte, bem como o detalhamento dos custos operacionais do veículo, conforme apresentado na Tabela 16.

\footnotetext{
${ }^{8}$ PIS - Programa de Integração Social, COFINS - Contribuição para o Financiamento da seguridade social, CSLL - Contribuição Social sobre Lucro Líquido, ICMS - Imposto sobre Circulação de Mercadorias e Serviços, IR - Imposto de Renda, Total de Impostos e Taxas.
} 
Tabela 16 - Detalhamento dos Custos Operacionais

\begin{tabular}{|c|c|c|c|c|}
\hline CUSTOS OPERACIONAIS & & Empresa & $\begin{array}{r}\text { Autônomo } \\
\text { (ideal) }\end{array}$ & $\begin{array}{r}\text { Autônomo } \\
\text { (prático) }\end{array}$ \\
\hline Custo Operacional Total & $\mathrm{R} \$ / \mathrm{mês}$ & 22.276 .887 & 19.465 .311 & 13.574 .505 \\
\hline Custo Operacional Total & $\mathrm{R} \$ / \mathrm{ano}$ & 267.322 .647 & 233.583 .729 & 162.894 .061 \\
\hline Custo p/ Veículo & $\mathrm{R} \$ / \mathrm{mês}$ & 69.834 & 61.020 & 42.553 \\
\hline Custo p/ Veículo & $\mathrm{R} \$ / \mathrm{ano}$ & 838.002 & 732.237 & 510.640 \\
\hline Custo $\mathrm{p} /$ Tonelada & $\mathrm{R} \$ / \mathrm{t}$ & 122,27 & 106,84 & 74,51 \\
\hline Custo p/ Quilômetro & $\mathrm{R} \$ / \mathrm{Km}$ & 7,21 & 6,3 & 4,4 \\
\hline Custo p/ Tonelada/Quilômetro & $\mathrm{R} \$ / \mathrm{t} * \mathrm{Km}$ & 0,28 & 0,24 & 0,17 \\
\hline Custo do Frete SP - RJ & $\mathbf{R} \$$ & 3.174 & 2.774 & 1.934 \\
\hline
\end{tabular}

Verifica-se, por meio da Tabela 16, que o preço do frete calculado para o autônomo prático $(\mathrm{R} \$ 1.934,24)$ é bastante semelhante ao preço pesquisado junto aos autônomos durante as pesquisas de campo ( $\mathrm{R} \$ 1.924,00)$, o que demonstra a confiabilidade do método utilizado.

Observa-se também que as empresas transportadoras recebem um frete inferior ao que seria justo segundo o método de cálculo baseado nos custos. O preço do frete calculado para a empresa $(\mathrm{R} \$ 3.174,25)$ é $7 \%$ superior ao que foi pesquisado junto às empresas em campo $(\mathrm{R} \$ 2.964,00)$, o que gera indícios de que os valores praticados pelas empresas no mercado de fretes estão distorcidos, conforme relatado pelos entrevistados. Isto é uma consequiência da comoditização do produto de transporte. Atualmente, não existem diferenças significativas entre as opções e níveis de serviços oferecidos pelos prestadores de serviços, de modo que as decisões dos clientes são baseadas apenas no custo. Esse fenômeno leva à queda da lucratividade e maior concorrência (Barat el al., 2007). A principal razão para isto é o grande número de empresas e autônomos existentes no mercado brasileiro. Em 1998, eram 34.500 empresas atuando no setor, enquanto hoje são cerca de 127.595 (Cibulska et al., 2010). Com relação ao número de transportadores autônomos, em 2007, havia 634.471 cadastros no Registro Nacional de Transportadores Rodoviários de Carga (RNTRC) e, em 2011, este número subiu para 1.285.343, crescimento superior a 54\%, mesmo tendo como base um crescimento de $42 \%$ do PIB no mesmo período (Dantas, 2012).

A Figura 2 permite uma melhor visualização da diferença dos valores de frete para os diferentes atores do mercado de transporte rodoviário de cargas no Brasil. 


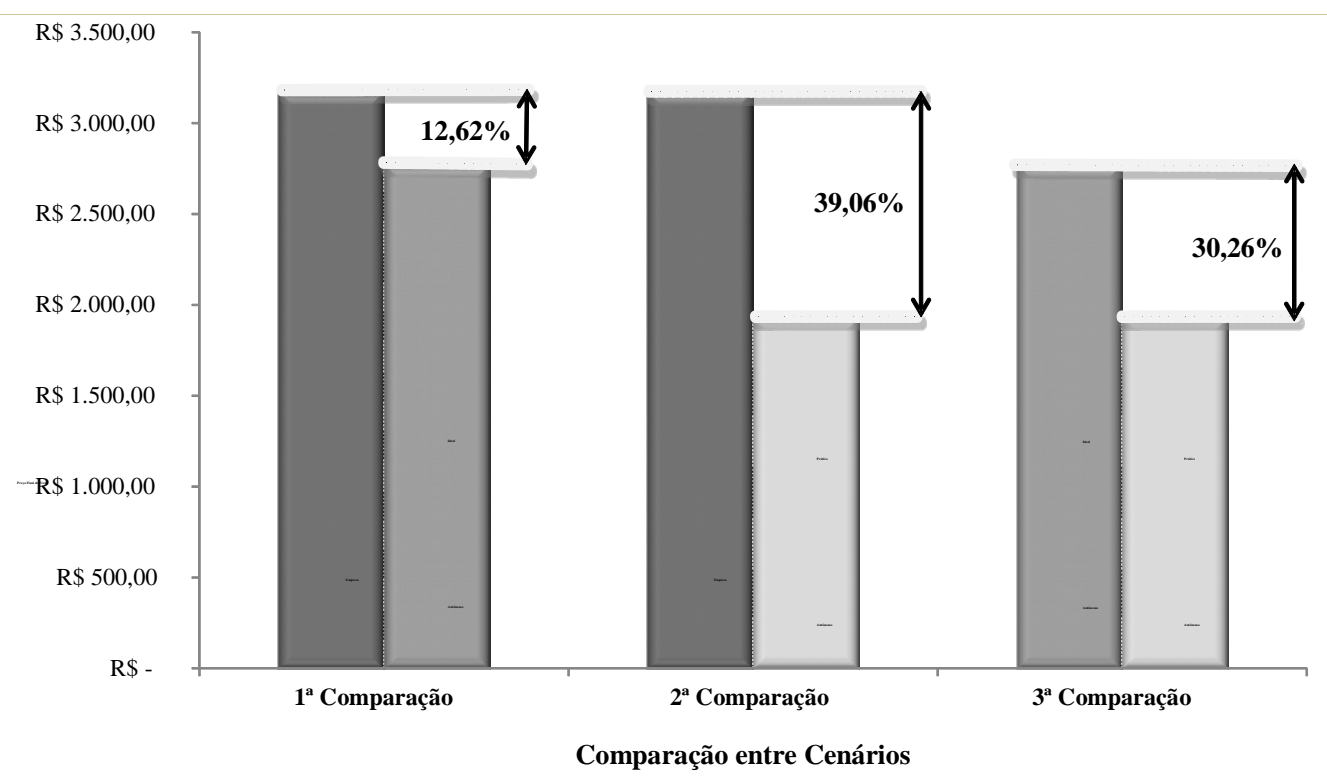

Figura 2 - Diferenças de Preços entre os Cenários Calculados

Pode-se observar que o preço do frete calculado para o autônomo prático é 39,06\% inferior ao preço do frete calculado para a empresa. Cabe ressaltar que, durante as pesquisas de campo, a diferença entre o preço do frete praticado pela empresa e o preço do frete praticado pelo autônomo foi de $35,09 \%$, bastante semelhante ao encontrado para o valor calculado.

Entretanto, a diferença do frete calculado para o autônomo ideal é, em média, 12,62\% menor do que o preço do frete calculado para a empresa. Desta forma, esta deveria ser a diferença real praticada no mercado entre o frete recebido pelas empresas transportadoras e o repassado aos transportadores autônomos. Assim, fica evidente que a comoditização do produto de transporte não gera a redução da lucratividade apenas para as empresas transportadoras, como discutido previamente, mas, de fato, há indícios que os autônomos estão sendo prejudicados, como relatam nas entrevistas. Considerando todos os custos que deveriam ser incorporados na composição do frete, o autônomo deveria receber $\mathrm{R} \$ 2.773,63$ de frete, enquanto, na prática, recebe $\mathrm{R} \$ 1.924,00$, ou seja, um valor $44 \%$ inferior ao que deveriam realmente receber. Isto se deve a grande oferta de serviços de autônomos, a prática de "valores tabelados" de fretes, sem oportunidades para a negociação e ao próprio desconhecimento, por parte dos autônomos de seus custos reais. Comparando-se ambos os autônomos pode-se constatar que o preço do frete calculado para o autônomo prático é 30,26\% inferior ao do autônomo ideal, ou seja, há uma diferença de 30,26\% entre o que o autônomo cobra pelo frete, na prática, e o que ele deveria realmente cobrar, se todos os custos fossem gerenciados de maneira correta. 
Em síntese, pode-se observar na tabela 17 que os autônomos não praticam todos os custos inerentes à empresa, como salários e encargos, aluguéis e tarifas de serviços públicos, por não possuírem uma estrutura administrativa. Entretanto, a empresa se beneficia da redução de alguns custos de aquisição de insumos operacionais pelo fato de comprar em grandes lotes, o que lhe confere poder de negociação junto aos fornecedores.

Tabela 17 - Distribuição dos Custos no Preço Final

\begin{tabular}{|c|c|c|c|c|}
\hline Grupo & Item & Empresa & $\begin{array}{r}\text { Autônomo } \\
\text { (ideal) }\end{array}$ & $\begin{array}{r}\text { Autônomo } \\
\text { (prático) }\end{array}$ \\
\hline \multirow{11}{*}{ Custos Fixos } & Remuneração do Capital & $\mathrm{R} \$ 158,90$ & $\mathrm{R} \$ 188,65$ & \\
\hline & Salário do Motorista & $\mathrm{R} \$ 289,35$ & $\mathrm{R} \$ 157,10$ & $\mathrm{R} \$ 78,55$ \\
\hline & Salário Oficina Mecânica & $\mathrm{R} \$ 28,94$ & - & - \\
\hline & Reposição do veículo & $\mathrm{R} \$ 144,24$ & $\mathrm{R} \$ 169,70$ & $\mathrm{R} \$ 33,59$ \\
\hline & Reposição do equipamento & $\mathrm{R} \$ 42,82$ & $\mathrm{R} \$ 50,38$ & $\mathrm{R} \$ 8,40$ \\
\hline & Licenciamento anual & $\mathrm{R} \$ 14,35$ & $\mathrm{R} \$ 16,77$ & $\mathrm{R} \$ 8,82$ \\
\hline & \begin{tabular}{|l|} 
Seguro do veículo \\
\end{tabular} & $\mathrm{R} \$ 67,07$ & $\mathrm{R} \$ 74,52$ & - \\
\hline & Seguro do equipamento & $\mathrm{R} \$ 14,49$ & $\mathrm{R} \$ 17,05$ & - \\
\hline & Responsaiblidade Civil & $\mathrm{R} \$ 7,35$ & $\mathrm{R} \$ 8,65$ & - \\
\hline & \begin{tabular}{|l|} 
Padronização \\
\end{tabular} & $\mathrm{R} \$ 4,50$ & - & - \\
\hline & Subtotal & R\$ 772,01 & $\mathrm{R} \$ 682,82$ & R\$ 129,35 \\
\hline \multirow{8}{*}{ Custos Variáveis } & Peças, acessórios e materiais de manutenção & $\mathrm{R} \$ 202,84$ & $\mathrm{R} \$ 238,64$ & $\mathrm{R} \$ 198,86$ \\
\hline & Combustíveis & $\mathrm{R} \$ 369,50$ & $\mathrm{R} \$ 420,00$ & $\mathrm{R} \$ 462,00$ \\
\hline & Lubrificantes do motor & $\mathrm{R} \$ 21,56$ & $\mathrm{R} \$ 25,67$ & $\mathrm{R} \$ 53,17$ \\
\hline & Lubrificantes de transmissão & $\mathrm{R} \$ 4,22$ & $\mathrm{R} \$ 5,02$ & $\mathrm{R} \$ 5,02$ \\
\hline & Lavagem e Engraxamento & $\mathrm{R} \$ 8,01$ & $\mathrm{R} \$ 11,44$ & $\mathrm{R} \$ 11,44$ \\
\hline & Pneus e recauchutagem & $\mathrm{R} \$ 96,12$ & $\mathrm{R} \$ 137,31$ & $\mathrm{R} \$ 135,28$ \\
\hline & Pedágios & $\mathrm{R} \$ 188,00$ & $\mathrm{R} \$ 376,00$ & $\mathrm{R} \$ 376,00$ \\
\hline & Subtotal & R\$ 890,25 & $\mathrm{R} \$ \mathbf{1 . 2 1 4 , 0 7}$ & $\mathbf{R} \$ 1.241,77$ \\
\hline \multirow{3}{*}{ Salários e Encargos } & Salários, Honorários e ordenados da diretoria & $\mathrm{R} \$ 18,14$ & & \\
\hline & Salários Profissionais de Escritório e operação do CD & $\mathrm{R} \$ 46,44$ & & \\
\hline & Subtotal & $\mathrm{R} \$ \mathbf{6 4 , 5 8}$ & $\mathbf{R} \$ \mathbf{0 , 0 0}$ & $\mathbf{R} \$ \mathbf{0 , 0 0}$ \\
\hline \multirow{5}{*}{ Outras Despesas } & Aluguéis & $\mathrm{R} \$ 7,69$ & - & \\
\hline & Tarifa de Serviço Público & $\mathrm{R} \$ 17,11$ & $\mathrm{R} \$ 18,18$ & $\mathrm{R} \$ 9,09$ \\
\hline & \begin{tabular}{|l|} 
Serviços Profissionais Terceirizados \\
\end{tabular} & $\mathrm{R} \$ 529,04$ & $\mathrm{R} \$ 538,60$ & $\mathrm{R} \$ 307,11$ \\
\hline & Depreciações & $\mathrm{R} \$ 2,60$ & - & - \\
\hline & Outros Custos Diversos & $\mathrm{R} \$ 47,32$ & $\mathrm{R} \$ 42,60$ & $\mathrm{R} \$ 53,51$ \\
\hline \multirow{3}{*}{ Lucros e Impostos } & Subtotal & $\mathrm{R} \$ 603,76$ & R\$ 599,38 & R\$ 369,70 \\
\hline & Lucro Operacional & $\mathrm{R} \$ 317,42$ & $\mathrm{R} \$ 277,36$ & $\mathrm{R} \$ 193,42$ \\
\hline & Impostos e Taxas & $\mathrm{R} \$ 526,22$ & - & \\
\hline & Subtotal & $\mathrm{R} \$ \mathbf{8 4 3 , 6 5}$ & $\mathrm{R} \$ \mathbf{2 7 7 , 3 6}$ & $\mathrm{R} \$ \mathbf{1 9 3 , 4 2}$ \\
\hline & Valor Final do Frete & $\mathrm{R} \$ \mathbf{3 . 1 7 4 , 2 5}$ & $\mathrm{R} \$ 2.773,63$ & R\$ 1.934,24 \\
\hline
\end{tabular}

Analisando-se o subtotal dos custos fixos, pode-se constatar que estes são bastante expressivos para o autônomo ideal $(24,62 \%)$ e para a empresa $(24,32 \%)$, mas de baixo peso na conta do autônomo prático $(6,69 \%)$. Por sua vez, os custos variáveis possuem grande expressividade no preço final do frete do autônomo prático $(64,20 \%)$, média expressividade para o autônomo ideal $(43,77 \%)$ e baixa para a empresa $(28,05 \%)$. 
Verifica-se, para os itens do grupo "Outras despesas" que são comum a todos os cenários, que a empresa e o autônomo prático têm custos proporcionalmente iguais ao valor final do frete, com cerca de $19 \%$, enquanto que o autônomo ideal terá custos proporcionais a 21,61\% para este mesmo item.

No item lucro operacional, a margem é proporcional à receita auferida pela operação e, portanto está compatível com cada cenário. Contudo, o item impostos e taxas é pago apenas pela empresa, uma vez que esta arca com todos os tributos e contribuições inerentes à operação de transporte de cargas. Os autônomos, por serem contratados, não pagarão estes impostos devido à característica de sua atividade profissional, que não prevê este tipo de pagamento segundo a legislação em vigor.

\section{Conclusão}

O presente estudo apresenta uma revisão das diferentes metodologias para o cálculo do frete rodoviário de carga com base na composição de custos, identificando as principais variáveis de cálculo. A partir desta revisão, propõe-se um método de cálculo de todos os custos envolvidos na operação de transporte. Em seguida, adotando-se o eixo São Paulo - Rio de Janeiro como objeto de estudo, foi desenvolvida uma pesquisa de campo para identificar o valor do frete cobrado pelos principais atores no mercado do transporte rodoviário de cargas, bem como suas principais características e peculiaridades na formação de fretes. Assim, tornou-se possível determinar o valor do frete que seria suficiente para remunerar todos os gastos percebidos pelo transportador autônomo e pelas empresas transportadoras em seu trabalho. Também foram realizadas comparações entre os fretes reais cobrados e os valores que deveriam ser praticados de fato.

Os preços praticados no mercado de fretes brasileiros não passam por nenhum controle governamental. Este fator tem como vantagem a abertura para a livre negociação e concorrência, entretanto, na prática, o que se pode observar é a imposição de valores preestabelecidos pelos contratantes deste serviço. Tais valores, que são obtidos por pesquisa das próprias empresas junto às concorrentes, nem sempre remuneram adequadamente os custos inerentes à operação de transporte. 
Por meio da análise dos custos de transporte no eixo São Paulo a Rio de Janeiro apresentada neste artigo, observa-se que os custos se comportam de forma bastante particular para cada um dos três cenários propostos. Cada cenário teve que arcar com determinados custos inerentes à sua realidade ou seu tipo de atuação no mercado de transporte rodoviário.

Ao final, pode-se observar que, se forem comparados os valores de frete pesquisados junto às empresas e os valores calculados para este cenário, há uma distorção, o que indica que o preço do frete cobrado pelas empresas também está defasado devido à comoditização do produto transporte. Porém, a maior distorção observada foi entre os valores praticados pelos autônomos e aquele calculado para o autônomo ideal, ou seja, para o transportador autônomo que tentaria arcar com todos os custos e gerenciamentos de maneira correta.

A análise do cenário do autônomo ideal possibilitou a comparação entre o que o autônomo deveria pagar de custos operacionais de transporte e o que ele realmente contabiliza. A partir desta comparação, conclui-se que, com os valores de fretes atualmente praticados no mercado de transporte, seria impossível para o transportador autônomo arcar com todos os custos operacionais e de gerenciamento, o que faz com que ele tenha que se submeter às distorções relacionadas à profissão, tais como: grande jornada de trabalho, dificuldade em trocar o veículo, negligenciar as manutenções do veículo, dentre outras.

Cabe salientar, no entanto, que tanto a empresa quanto o autônomo que possuem os preços do frete distorcidos precisam operar no mercado tentando se adequar a esta distorção, caso contrário poderão perder contratos de fretes. Assim, mesmo sabendo que estão com os preços abaixo do que seria correto, ambos precisam ajustar seus custos de tal modo que ainda permaneçam competitivos no mercado de fretes. Ressalta-se que, apesar de ter sido adotado como objeto de estudo o eixo São Paulo - Rio de Janeiro, que é um dos maiores corredores de transporte de carga rodoviária no Brasil, os resultados desta pesquisa não podem ser generalizados para todo o país. Desta forma, considera-se importante que outras pesquisas sejam realizadas em outras regiões do país, em especial na região Centro-oeste, devido ao escoamento de importantes commodities agrícolas. 


\section{Referências}

Agência Nacional de Transportes Terrestres - ANTT (2012) Disponível em www.antt.gov.br.

Associação Brasileira de Transportadores Internacionais - ABTI (2012) Multa para as empresas por utilização da Carta - Frete. Disponível em www.abti.org.br/index.php.

Associação Nacional do Transporte de Cargas - NTC (2001) Manual de cálculo de custos e formação de preços do transporte rodoviário de cargas. São Paulo. Disponível em www.cnt.org.br.

Associação Nacional do Transporte de Cargas - NTC (2010) Roubo de Cargas. Disponível em www.cnt.org.br.

Barat, J., Vidigal, A., Gandra, M. e Dupas, G. (2007) Logística e transporte no processo de globalização: oportunidades para o Brasil. São Paulo: UNESP.

Batti, D. (2009) Estudo sobre a utilização da modalidade aérea em substituição à modalidade rodoviária em determinadas condições. Dissertação (Mestrado em Ciências), Universidade Federal de Uberlândia, Minas Gerais.

Caixeta Filho, J. e Martins, R. (2011) Gestão logística do transporte de cargas, São Paulo: Atlas.

Chahad, J. e Cacciamali, M. (2011) As transformações estruturais no setor de transporte rodoviário e a reorganização no mercado de trabalho do motorista de caminhão no Brasil. Disponível em www.fea.usp.br/feaecon//biblioteca.

Caldas, M. e Caldas, V. (2004) Análise dos custos de distribuição em regiões metropolitanas. Anais do Congresso Rencontre Internacionale de Recherche Logistique, Fortaleza.

Cibulska, P., Tedesco, G., Villela, T. e Granemann, S. (2010) Panorama da frota dos transportadores rodoviários remunerados de cargas no Brasil. XVI Congresso Pan-Americano de Engenharia de Tráfego e Transportes e Logística. Portugal.

Confederação Nacional dos Transportes - CNT (2002) Transporte de carga no Brasil, ameaças e oportunidades para o desenvolvimento do país - Diagnóstico e Plano de Ação. Disponível em www.cnt.org.br.

Confederação Nacional dos Transportes - CNT (2002) Pesquisa CNT de Rodovias 2010: relatório gerencial. Disponível em www.cnt.org.br.

Confederação Nacional dos Transportes - CNT (2011) Plano CNT de transporte e logística. Disponível em www.cnt.org.br.

Dantas, J. A. (2012) Os grandes entraves no transporte rodoviário de cargas. Transpo on line, 14 de fevereiro de 2012. Disponível em www.transpoonline.com.br.

Dos Reis, N. (2001) Regulamentação do transporte rodoviário de cargas no Brasil e no Mundo. Disponível www.ntcnet.org.br/regtrc. 2001.

Fleury, P. (2003) Nota sobre o setor de transporte de cargas no Brasil. Rio de Janeiro: ILLOS Instituto de Logística e Supply Chain.

Hijjar, M. (2008) Preços de frete rodoviário no Brasil. Rio de Janeiro: ILLOS- Instituto de Logística e Supply Chain.

Instituto Brasileiro de Geografia e Estatística - IBGE (2007) Pesquisa dos principais produtos e serviços. Disponível em www.ibge.gov.br. 
Lima, M. (2003) Custeio do transporte rodoviário de cargas. In: Figueiredo, K. F., Fleury, P. F. e Wanke, P. (Eds.) Logística e gerenciamento da cadeia de suprimentos: planejamento do fluxo de produtos e de recursos. São Paulo: Editora Atlas.

Lima, R.(2006) Benchmarking de tarifas e práticas do transporte rodoviário. Portal Logística Total. Disponível em www.logisticatotal.com.br/artigos.

Martins, S. (2008) Estudo da formação do frete rodoviário e potencial de conflitos em negociações. cadeias do agronegócio Brasileiro,vol. 10, n. 1, pp. 73-87. Disponível:http://revista.dae.ufla.br.

Ortúzar, J. e Willumsen, L. (1994) Modelling Transport. West Sussex: John Wiley.

Receita Federal (2012) Disponível em www.receita.fazenda.gov.br.

Registro Nacional dos Transportadores Rodoviários de Cargas - RNTRC (2011) Disponível em www.antt.gov.br.

Silva, E. (2006) Centralização da distribuição e custos de transportes: estudo de caso da Ambev. Dissertação (Mestrado em Ciências), Universidade Federal do Rio de Janeiro, Rio de Janeiro.

Soares, M. e Caixeta, F. (1997) Caracterização do mercado de fretes rodoviários para produtos agrícolas. São Paulo. Disponível em www.log.esalq.usp.br.

Souza, B. e Rocha, W. (2010) Modelo de análise de lucro na logística: conceitos importantes para as decisões. Revista Mundo Logística, vol. 17.

Teixeira Filho, J.(2001) Modelos analíticos de fretes cobrados para o transporte de cargas. Rio de Dissertação (Mestrado em Ciências), Instituto Militar de Engenharia, Rio de Janeiro.

Teixeira, K. (2007) Investigação de opções de transportes de carga geral em contêineres nas conexões com a região Amazônica. Dissertação (Mestrado em Ciências), Universidade de São Paulo, São Paulo.

Valente, A., Novaes, A., Passaglia, E. e Vieira, H. (2011) Gerenciamento de transporte e frotas. São Paulo: Pioneira.

Wanke, P. (2010) Logística e transporte de cargas no Brasil: produtividade e eficiência no Século XXI. São Paulo: Atlas. 